NBER WORKING PAPER SERIES

\title{
CONFLICTS OF INTEREST, INFORMATION PROVISION, AND COMPETITION IN BANKING
}

\author{
Patrick Bolton \\ Xavier Freixas \\ Joel Shapiro \\ Working Paper 10571 \\ http://www.nber.org/papers/w10571
NATIONAL BUREAU OF ECONOMIC RESEARCH
1050 Massachusetts Avenue
Cambridge, MA 02138
June 2004

Financial support from the Fondation Banque de France and Barcelona Economics (CREA) is gratefully acknowledged. Shapiro also acknowledges the nancial support from DGES under BEC 2000-1026 and BEC2003-00412.We thank Ricardo Fuentes and Judit Montoriol for their research assistance. We also thank Fabrizio Germano, Joseph Harrington, Edi Karni, Sjaak Hurkens, Giancarlo Spagnolo and audiences at the Banque de France, Columbia, Johns Hopkins, UAB, the Econometric Society NASM 2003 and NAWM 2004, and European Finance Association 2003 Meetings for helpful discussions. The views expressed herein are those of the author(s) and not necessarily those of the National Bureau of Economic Research.

(C2004 by Patrick Bolton, Xavier Freixas, and Joel Shapiro. All rights reserved. Short sections of text, not to exceed two paragraphs, may be quoted without explicit permission provided that full credit, including (C) notice, is given to the source. 
Conflicts of Interest, Information Provision, and Competition in Banking

Patrick Bolton, Xavier Freixas, and Joel Shapiro

NBER Working Paper No. 10571

June 2004

JEL No. G2, L1

\section{$\underline{\text { ABSTRACT }}$}

In some markets, such as the market for drugs or for financial services, sellers have better information than buyers regarding the matching between the buyer's needs and the good's actual characteristics. Depending on the market structure, this may lead to conflicts of interest and/or the under-provision of information by the seller. This paper studies this issue in the market for financial services. The analysis presents a new model of competition between banks, as banks' price competition influences the ensuing incentives for truthful information revelation. We compare two different firm structures, specialized banking, where financial institutions provide a unique financial product, and one-stop banking, where a financial institution is able to provide several financial products which are horizontally differentiated. We show first that, although conflicts of interest may prevent information disclosure under monopoly, competition forces full information provision for sufficiently high reputation costs. Second, in the presence of market power, one-stop banks will use information strategically to increase product differentiation and therefore will always provide reliable information and charge higher prices than specialized banks, thus providing a new reason for the creation of one-stop banks. Finally, we show that, if independent financial advisers are able to provide reliable information, this increases product differentiation and therefore market power, so that it is in the interest of financial intermediaries to promote external independent financial advice.

$\begin{array}{lll}\text { Patrick Bolton } & \text { Xavier Freixas } & \text { Joel Shapiro } \\ \text { Princeton University } & \text { Universitat Pompeu Fabra } & \text { Universitat Pompeu Fabra } \\ \text { Bendheim Center for Finance } & \text { Ramon Trias Fargas, 25-27 } & \text { Ramon Trias Fargas, 25-27 } \\ \text { 26 Prospect Avenue } & \text { 08005 Barcelona Spain } & \text { 08005 Barcelona Spain } \\ \text { Princeton, NJ 08540-5296 } & \text { xavier.freixas@upf.edu } & \text { joel.shapiro@upf.edu } \\ \text { and NBER } & & \\ \text { pbolton@princeton.edu } & & \end{array}$




\section{Introduction}

This paper is concerned with the provision of information by sellers of financial services to customers when the financial products are horizontally differentiated. The issue of information provision is timely, as the banking industry is evolving from the traditional business of financial intermediation towards a fee-based industry where information is crucial in providing more added value to customers. In a departure from the standard finance literature, we make the assumption that some investors are partially uninformed in the sense that they don't know the financial product that best suits their needs. This innovative assumption allows for a rich environment where different types of phenomena such as misselling of financial products might occur. Although information is valuable to customers, the sellers face a fundamental conflict of interest problem: should a financial intermediary tell a client that another firm offers a product that better suits the client's needs? Our results directly challenge the conventional wisdom that information is only credible if it is produced from an independent institution that has no conflict of interests. We find that in different environments, competition or consolidation (into one-stop banks) can solve the apparent conflicts of interest.

In addition to horizontal differentiation and customers' imperfect information, our setting is characterized by two additional assumptions that we deem natural in the financial industry: non-verifiable information and reputation costs for misselling. In a heavily regulated environment, the disclosure of verifiable information can be made compulsory and any attempt to falsify it can be heavily penalized. This then leaves open the issue of inducing revelation of non-verifiable information. Since financial institutions often care about establishing a relationship with their clients, however, some discipline can be imposed in the revelation of non-verifiable information through the reputation costs institutions bear for giving misleading advice.

Although our research is originally motivated by the issues relevant to the financial industry, our findings apply to any market where buyers are uncertain about which product is best for them and where sellers face a reputation cost if they provide misleading information. Examples of such markets outside the financial industry could be the market for medicine, where information is provided by physicians, the market for real estate, and the market for sophisticated technical equipment. Moreover, the issue of how informative information provision is and how it affects competition is 
important to discussions of markets where advertising is used ${ }^{1}$.

Our main findings can be summarized as follows. Competition among specialized financial intermediaries leads to full credible information disclosure, even for small but strictly positive reputation costs that are bounded away from zero. The basic intuition for this result is that competition may eliminate the potential conflict of interest by reducing the gains from lying and by inducing banks to differentiate their product by providing credible information. Banks can thus restore their margins on a smaller base of customers that have a special need for their product. However, the size of reputation costs limit profit margins because of the need to remain credible in giving advice to clients. As a consequence, sellers could gain from the presence of a third party (for instance some independent financial advisor) that could provide information, allowing them to raise prices further.

One-stop banks (defined here as banks that sell multiple products) can also overcome this conflict of interest in certain circumstances. While the usual explanation for the creation of one-stop banks is based on an economies of scope argument that it is more efficient to sell multiple financial products from the same outlet, we find that the ability to credibly provide information may be another major motive for consolidation. One-stop banks are able to provide reliable information and charge higher prices than specialized banks when they have market power. Otherwise, competition with one-stop banks results in a similar outcome as competition with specialized banks.

The main theoretical novelty of the paper is that firms' actions (the prices they set) define an ensuing signaling game (the advice banks give to customers). These actions commit the firms to credible or non-credible information revelation by providing incentives to tell the truth or not. Most other signaling models have payoffs determined by current or future actions, not past actions as in our model. Moreover, these models have each firm signaling its private information, such as in Mailath (1989). Here, the private information is the information acquired by a bank about its customer's financial profile, which it can reveal as it wishes.

Our model incorporates several elements from the industrial organization literature. As all customers are uncertain of which product they prefer, there are flavors of both horizontal differentiation (Hotelling, 1929) and vertical differentiation (Shaked and Sutton, 1983). In order to provide information to customers, we assume that banks make unverifiable statements about which

\footnotetext{
${ }^{1}$ See for example, Meurer and Stahl (1994).
} 
product is best for the customer. This is a form of information revelation game in which talk is not cheap. In contrast, most other models that have been considered in the literature involve agents providing information that is either cheap talk or verifiable. As is well known, when private information is verifiable, voluntary disclosure often leads to full information revelation (see Grossman and Hart, 1980, Milgrom and Roberts, 1986, and Okuno-Fujiwara, Postlewaite, and Suzumura, 1990). In our setup, we allow for lying, but make it costly by introducing a reputation cost.

The issue of the market provision of information prior to a sale has been discussed in different settings. For example, Benabou and Laroque (1992) and Morgan and Stocken (2003) discuss a conflict of interest similar to the one we look at in the context of stock recommendations. However, our analysis focuses on direct price competition between information providers, while they consider information providers that benefit from subsequent movements in the secondary market price of a recommended stock.

The environment we discuss resembles in some ways the literature on credence goods, first discussed in Darby and Karni (1973). For such goods or services the consumer is never able to completely ascertain the quality of the good and must rely on the advice of experts (an example of a credence service is automobile repairs - all one knows is whether the car functions properly, not whether the repair was necessary or well executed). Several papers that discuss credence goods are interested in credible revelation of information (Pitchik and Schotter (1987), Emons (1997, 2001)) and in competition among credence good providers (Wolinsky, 1993 and Pesendorfer and Wolinsky, 2003). In our model, however, the financial instruments are also partially experience goods, since we allow for a reputation cost for misleading customers. Another difference with the literature on information revelation and credence goods is that prices are not signals in our model, but instead provide incentives for information revelation.

The problem we analyze is also related to the literature on referrals. In a recent contribution Garicano and Santos (2004) discuss efficiency in matching clients with the correct agents when referrals are possible. Since agents may have private information about a client's value, there is an adverse selection problem. In addition, they allow for moral hazard in effort provision in helping the client. We allow for costless referrals and focus on the potential for price competition to provide incentives for revealing information (whereas they abstract away from competition for customers to focus on the allocation problem). They find that partnerships may provide incentives to allocate 
clients efficiently, much as we find one-stop banks have greater incentives to match customers correctly to products, although for different reasons - partnerships create a moral hazard problem for the referrer, weakening incentives to lie about the project.

Finally, Demski and Sappington's (1987) and Shavell's (1994) contributions also deal with the issue of information acquisition and disclosure but in a different setting from ours. In Demski and Sappington (1987) the service provided by the agent is a form of credence good and the agent can only be given incentives to acquire information with an output-based compensation scheme. In contrast, in Shavell (1994) information is verifiable but whether the agent has acquired the information is not observable. To be able to limit information disclosure ex-post the agent then has an incentive not to always acquire the information. But the largest difference with our analysis is that we permit Bertrand competition between sellers, while both Shavell (1984) and Demski and Sappington (1987) focus on bilateral buyer-seller contracting relations.

The paper is organized as follows: Section 2 is devoted to a description of the model. Section 3 studies the benchmark case of monopoly banks. Section 4 considers information production and competition among specialized banks and in Section 5 we study how incentives change when one-stop banks are present. In Section 6 we analyze market structure, while in Section 7 we study the case where the bank investment in the production of information is not observable. Finally, Section 8 concludes.

\section{The model}

We consider a model where two financial intermediaries (FIs) compete by offering one or possibly two different types of financial products, which we label simply as $A$ and $B$. A working example which we will refer to in this article is life insurance and pension funds, two substitute savings vehicles with different appeal for different households depending on their tax situation, savings horizon and idiosyncratic income shocks. 


\subsection{Customers}

For simplicity, we take bank customers to be risk neutral households who buy at most one unit of a financial product from an FI. ${ }^{2}$

We assume that customers could be of two different types, $A$ and $B$, reflecting their different tax status, say. Type $A$ investors matched with product $A$ derive a gross payoff $R$, while when they get product $B$ they only get a payoff $r(r<R)$. Similarly, for type $B$ investors, when matched with product $B$ they get a payoff $R$ and when mismatched they get $r$. We denote by $\Delta$ the difference $R-r$.

Customers do not know which of the two products is best suited for their needs. For example, they may be unaware of important tax advantages of one of the products or they may not be aware of specific contractual clauses such as foreclosure penalties. We model this lack of knowledge as incomplete information about their true type. ${ }^{3}$ Thus, all they know is the prior probability of being of type $A$, which is denoted by $q$. In addition, we assume that this prior probability is equal to the true proportion of type $A$ customers, and that $q>\frac{1}{2}$ (without loss of generality). Given this information and the prices of the financial products posted by the FIs, customers choose which FI to approach. This choice will depend not only on the product's price but also on whether the FI is expected to provide reliable information on the customers' types. Should a customer approaching FI $A$, say, obtain information that FI $B$ offers the best deal (better matched product at competitive terms) then she will switch to FI $B$. In our basic model, we assume that a firm's investment in information provision technology is observable. We abandon this assumption in Section 7. We also assume that the switching cost technology is such that a customer may switch between banks only once ${ }^{45}$.

\footnotetext{
${ }^{2}$ An alternative interpretation may also be that customers are firms choosing between alternative financial structures.

${ }^{3}$ Equivalently, we could interpret this lack of knowledge as incomplete information about the type of the financial product that matches each customer's needs.

${ }^{4}$ Pesendorfer and Wolinsky (2003) consider situations where uninformed customers may seek second opinions. In their model, however, sellers can only communicate noisy information to their customers.

${ }^{5}$ In the U.S., the average number of banks with which small businesses have relationships is 1.5 ( $60 \%$ of businesses only have relationships with 1 bank, $26 \%$ with two banks) which indicates that businesses tend to minimize their number of relationships. If we extend this by adding all financial institutions, the average number is 2 ( $42 \%$ of businesses only have relationships with one bank or institution, $28 \%$ with two). This data is taken from the National Survey of Small Business Finances (NSSBF) 1998.
} 


\subsection{Financial Intermediaries}

We consider two types of FIs, specialized FIs and one-stop banks. A specialized FI is one that offers only one financial product. A one-stop bank offers both types of financial product ${ }^{6}$.

The cost of production for the two products is the same and is normalized to zero. This means that the prices of the two products, $p_{A}$ and $p_{B}$ are to be interpreted as spreads.

Although customers do not know their type, FIs may know which product best fits the needs of each customer. FIs can offer an advisory service and guide customers to the relevant product but they may face a conflict of interest problem in their dual role as financial advisors and sellers of financial products. This conflict of interest puts them in a position where they may not be able to credibly communicate their information about a good match to customers since they have an incentive to peddle their own product. Customers understand this and will only follow an FI's recommendation if it is in the FI's interest to truthfully reveal its information.

An FI's incentive is driven in part by a concern to maintain a reputation for honest advice and by competitive pressure, which limits the FI's ability to benefit from its provision of information. To model this reputational concern we assume that an FI suffers a reputation loss of $\rho$ when a lie told to a customer leads to a purchase by that customer. We interpret this as a loss of future business from that customer or from word-of-mouth due to the bank's deliberately misleading or confusing advice. In the appendix (section 10.6) we examine the robustness of the model with a more general definition of reputation ${ }^{7}$. We also find similar results to those of the text when the reputation cost is endogenized ${ }^{8}$.

\footnotetext{
${ }^{6}$ The terms universal bank or financial conglomerate are also commonly used to describe a one-stop bank. We prefer the term one-stop bank since the first term carries a connotation of economies of scope and the second a connotation of regulatory arbitrage, which are both absent from our framework.

${ }^{7}$ In this more general definition, we allow for two reputation costs. One reputation cost is incurred when the FI lies and misleads the customer into purchasing the wrong product. The other reputation cost is incurred when the FI lies but doesn't mislead the customer. This analysis is less tractable (partially revealing equilibria are not trivial) but yields essentially the same equilibrium as the model we analyze.

${ }^{8}$ Specifically, if the reputation cost takes the form $\bar{\rho}+\theta \pi$, where $\bar{\rho}$ is an exogenous fixed cost and $\theta \pi$ is an endogenous cost that varies with current sales (with $\theta<1$ ), the model maintains exactly the same structure and results (instead of a cutoff of $\rho$ for information regimes, the cutoff is $\left.\frac{\bar{\rho}}{1-\theta}\right)$. It is important that some part of the reputation cost be
} 
Obviously, if this reputational loss is very large then the FIs' incentive to peddle their products disappears. This is why we assume that:

Assumption A1: $\operatorname{Min}(\Delta, r)>\rho$.

This assumption allows us to focus on the more relevant case where a conflict of interest arises. If $\rho$ is too large, then there is no choice but to reveal full information since the firm will be strictly punished for not doing so. Although we have placed an upper bound on $\rho$, we allow $\rho$ to be as low as zero, in which case we are analyzing a pure cheap talk game.

We restrict the customers' strategies with the following assumption:

Assumption A2: There is a tiny amount of uncertainty on the part of firms about the actual values of $\rho$ and $R$, i.e. $\rho \in\left[\tilde{\rho}-\varepsilon_{1}, \tilde{\rho}+\varepsilon_{1}\right]$ and $R \in\left[\tilde{R}-\varepsilon_{2}, \tilde{R}+\varepsilon_{2}\right]$ such that $\varepsilon_{1}, \varepsilon_{2} \rightarrow 0$.

For any small amount of uncertainty, however small, firms are unable to set prices exactly at levels to make consumers indifferent between choices (or to balance the reputation effect). Thus, this small uncertainty limits customers to pure strategies and eliminates multiple equilibria.

\subsection{Timing}

1. FIs decide whether to invest in information provision technology.

2. FIs set prices. To simplify the strategic analysis we will give one of the FIs a price leadership role (that is, one of the FIs moves first in setting prices).

3. Investors approach an FI, which then recommends a financial product.

4. Investors make a decision on which product to purchase at which FI, based on observed prices and the FI's recommendation.

We begin with a brief analysis of monopoly banking.

exogenous. One possible interpretation of this exogenous part is that it represents a loss in profits on other unrelated financial products (such as deposits) or businesses run by the bank. Another possibility is that it represents a part of future demand growth. 


\section{$3 \quad$ Monopoly Banking}

\subsection{A specialized monopoly}

Under no information provision, a specialized monopoly FI sets the monopoly spread at either $r+q \Delta$ for an $A$ bank, or $r+(1-q) \Delta$ for a $B$ bank. Under full information a specialized bank either serves all customers at a maximum spread of $r$ or it only serves well matched customers at a monopoly spread of $R$. The latter policy is optimal for FI $A$ if and only if $r \leq q R$.

It is obvious then, that either FI monopoly strictly prefers consumers to be uninformed, as it can then sell to both types at a sufficiently large spread. Assuming that the specialized bank has the ability to convey information about customer types, the above results indicate that the incentive to reveal information is quite low. Indeed, analyzing the pricing decision and the signaling game (where customers must purchase product $i=A, B$ or receive their reservation utility of zero, and the FI can say whether product $i$ is a good or bad match) in the appendix we prove:

Proposition 1 Under assumptions $A 1$ and A2, a monopoly FI $A$ reveals no information (always recommends product $A$ ) and sets price $p_{A}=r+q \Delta$. $A$ monopoly FI $B$ reveals no information (always recommends product $B$ ) if $\rho<\frac{1-q}{q} \Delta$ and sets price $p_{B}=r+(1-q) \Delta$. If $\rho>\frac{1-q}{q} \Delta$, FI B sets $p_{B}=r$ and fully reveals its information.

At an intuitive level, the rationale is the following. For any price above $r$, the monopoly can't reveal any information and get stuck with only the customers of its type, because it would then prefer to deviate and grab all of the customers. Given an investment in information provision, the rents from selling to all of the market always outweigh the reputation cost of lying to a fraction of the customers for FI $A$ (under assumption A1) and sometimes for FI B.

This logic, which is present as well in comparing the no information case to the full information case, disappears when competition is introduced, as we will see in the following sections. The advantage of having a captive audience that has high valuations for the product drives this reversal. 


\subsection{Monopoly Pricing of a one-stop bank}

The key difference between a specialized and a one-stop FI is that the latter will find it much easier to overcome the conflict of interest problem in the provision of information. This can be explained by the fact that provision of information need no longer result in any loss of clientele. This is an important potential benefit of one-stop banks emphasized by bankers who deal with the marketing of financial products.

We now assume that one FI, which we will call FI 1, offers both financial products $A$ and $B$ without competition at prices $p_{1 A}$ and $p_{1 B}$, and refer to this FI as a one-stop bank. Market power gives the FI leverage in pricing, but it cannot fully extract consumer rents if consumers are uncertain about their types and it is unable to provide information. In this case, the best that the FI can do would be to set $p_{1 A}$ equal to $r+q \Delta$, and set $p_{1 B}$ so that no one will purchase product $B$ (i.e. $p_{1 B}>r+(1-q) \Delta$ ). The one-stop bank then does not even sell both products, it sells the one for which customers have a higher ex-ante valuation. Its actions emulate those of a specialized bank.

In the case where the one-stop bank can provide information, product $B$ is sold to type $B$ customers. The one-stop bank is able to segment the market and extract full rents by providing full information.

Proposition 2 A monopoly one-stop bank fully reveals information, customers purchase the product which matches their type, and prices are $p_{1 A}=$ $p_{1 B}=R$.

The proof is in the appendix. Note that when $\rho>0$, the one-stop bank can credibly reveal the information it has about customer types. The reason is simply that by making the prices of the two products close to each other, it eliminates the incentive to misdirect the customer, and saves the reputation cost $\rho$ when it tells the truth. By setting the prices equal to $R$, the bank can tell the truth and simultaneously extract all rents. When $\rho=0$ the bank is indifferent and one equilibrium is for the bank to tell the truth.

This section highlights a simple but important economic principle, which is that monopoly one-stop banks are better able to overcome the conflict of interest problem in advising their clients on what product is best for them. We shall now see, however, that when there is competition among banks this general principle is no longer valid. Put simply, competition induces 
information revelation whether it is between specialized banks or with a onestop bank. ${ }^{9}$

\section{Competition among Specialized FIs}

This section determines under what conditions, if any, a specialized FI has incentives to provide information to its customers in equilibrium. As we have already pointed out, specialized FIs have a conflict of interest in advising their prospective customers to bank at the competitor FI. At the same time, truthful revelation increases the customers' valuations for their own products. These diverging incentives determine the equilibrium amount of revelation. Before analyzing the FIs' incentives for truthful revelation it is helpful to first consider the extreme situations of no information revelation and full information disclosure.

\subsection{Competition with no information}

In the absence of any additional information, a customer buys product $A$ provided by the FI specialized in $A$ services if and only if:

$$
q R+(1-q) r-p_{A} \geq q r+(1-q) R-p_{B}
$$

That is, if and only if

$$
(2 q-1) \Delta \geq p_{A}-p_{B}
$$

Thus, FI $A$ will set a price $p_{A}=(2 q-1) \Delta$, forcing FI $B$ to zero profits ${ }^{10}$. For this price level the customer's participation constraint is satisfied:

$$
q R+(1-q) r-(2 q-1) \Delta=R-q \Delta \geq 0
$$

\footnotetext{
${ }^{9}$ We take the reputation cost per customer incurred when lying as exogenously fixed at $\rho$. It might be argued, however, that the reputation cost varies with market structure. To the extent that monopolists extract larger mark-ups they may be more wary of losing future customers. On the other hand, monopolists face a captive demand, which makes them less concerned about losing business to competitors. How these countervailing effects play out requires a more detailed analysis, which is beyond the scope of this paper.

${ }^{10}$ That is, assuming that FI $A$ is the price leader. If FI $B$ is the price leader, there is a continuum of equilibria each with a different $p_{B}$ that is 'undercut' by FI $A$ with a best response $p_{A}=\min \left[(2 q-1) \Delta+p_{B}, q R+(1-q) r\right]$ (since FI $B$ always makes zero profits it does not care which $p_{B}$ it sets). Note that the equilibrium when FI $A$ is the price leader is included in this set.
} 
As is intuitive, the larger the product differentiation $\Delta$ and the larger the probability that customers are of type $A$, the larger the price difference and $A^{\prime}$ s profits. The closer $\Delta$ is to zero and/or the closer $q$ is to $\frac{1}{2}$ the more intense the competition between FIs and the larger is the customer's surplus, as the two products become close substitutes from the perspective of uninformed customers. Absent any information, FI $B$ makes zero profits due to the ex-ante preference of customers for product $A$.

\subsection{Competition under full information}

Suppose that a customer knows her true type. All $A$-customers are then likely to bank at FI $A$, and all $B$-customers to bank at FI $B$. In other words, each FI is then likely to have a captive clientele. This will have the effect of dampening price competition as each FI will be reluctant to cut prices low enough to attract mismatched customers. It is not surprising then that the following proposition should hold:

Proposition 3 Under full information, if FI $A$ is the price leader, the equilibrium prices are

i) If $q R<2 \Delta, p_{A}=\min [(1-q) R+\Delta, R], p_{B}=R$, and profits are $\pi_{A}=q p_{A}$ and $\pi_{B}=(1-q) R$

ii) if $q R>2 \Delta, p_{A}=\frac{2-q}{q} \Delta, p_{B}=\frac{2}{q} \Delta$, and profits are $\pi_{A}=(2-q) \Delta$ and $\pi_{B}=\frac{2(1-q)}{q} \Delta$.

This is proven in the appendix. Note that if FI $B$ becomes the price leader, the results are symmetric (switch $A$ for $B$ and $q$ for $1-q$ ).

The comparison with the absence of information case points out the mitigating effect of quality uncertainty (Bester (1998)). Information production increases efficiency (total surplus here is $R$, compared to $q R+(1-q) r$ in the no information case), but it also decreases competition through higher prices as every firm now has market power over its own type. We will now show however that this monopoly power is impaired by the FIs' conflict of interest problem in advising its customers.

\subsection{Competition under credible information produc- tion}

When FIs must be induced to give honest advice they are in a weaker position to exploit their local monopoly power. The reason is simply that if they 
charge high prices and also recommend their expensive product to prospective customers, this recommendation is not credible.

Once FIs have set their prices and customers have made their decision on which FI to approach, an FI that has invested in information provision can ascertain the true types of customers. We analyze the incentives of this FI to provide information in the signaling game where the FI's type is its information about the customer.

\subsubsection{The information revelation game for a specialized FI}

An FI's strategy can be summarized by two variables: the probability $\alpha$ that a type $A$ customer is correctly advised to choose product $A$ and the probability $\beta$ that a type $B$ customer is wrongly advised to take product $A$.

Having received a recommendation $\widehat{A}$ to purchase product $A$, or $\widehat{B}$ to purchase product $B$, a customer's strategy can be described, symmetrically, by the probability $a$ of following the advice to take product $A$, and the probability $b$ of following the advice to take product $B$. Figure 1 shows the basic information revelation game structure.

We begin by characterizing Perfect Bayesian Equilibria in the information revelation game of FI $A$, taking as given the prices quoted by the FIs and the customers' decisions as to which FI to approach. In a second step we shall move back in the game tree and solve for the equilibrium prices and customer decisions on where to bank in the full game. In a Perfect Bayesian Equilibrium, each agent optimally chooses its strategy given equilibrium (and out-of-equilibrium) beliefs and the other agents' strategies. For out-of-equilibrium beliefs we rely on the Cho-Kreps (1987) intuitive criterion to pin down beliefs.

FIs maximize their profits net of the reputation cost of lying. So, when FI $A$ observes a type $A$ customer the necessary condition for FI $A$ to truthfully reveal $A$ 's type is:

$$
a p_{A} \geq(1-b)\left(p_{A}-\rho\right),
$$

or equivalently, using the notation $\equiv$ to mean "defined by":

$$
\Delta \pi_{A}(A) \equiv(a+b-1) p_{A}+(1-b) \rho \geq 0
$$

Symmetrically, when FI $A$ observes a type $B$ customer, the necessary condition for FI $A$ to truthfully reveal $B$ 's type is:

$$
\Delta \pi_{A}(B) \equiv-(a+b-1) p_{A}+a \rho \geq 0
$$




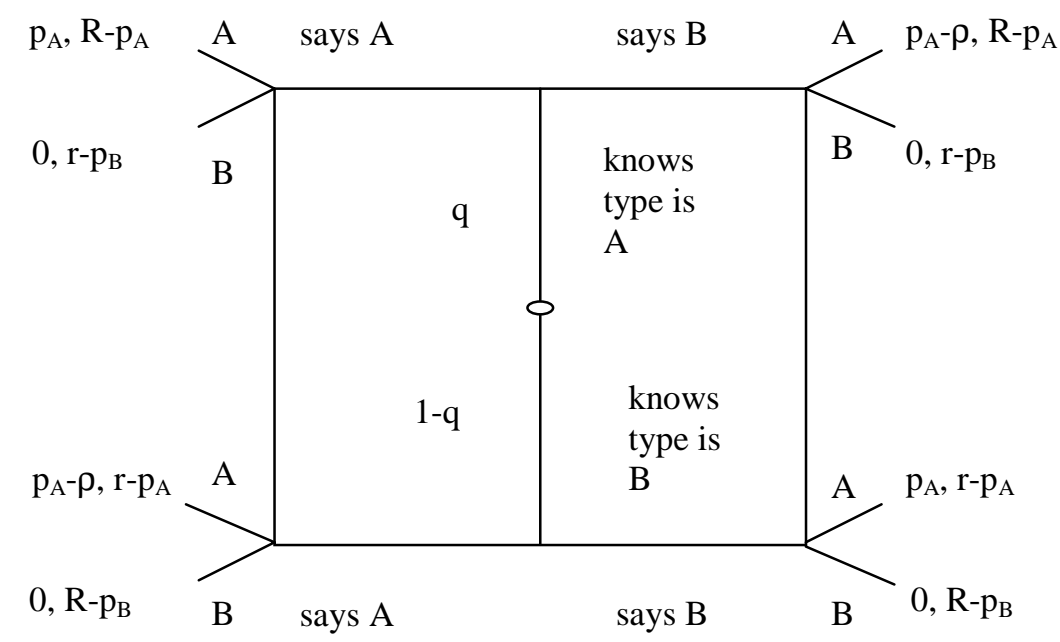

Figure 1: The Information Revelation Game

In general, FIs may play mixed strategies.

Customers use equilibrium updated beliefs, when they receive a recommendation, to compute their optimal strategies. Under assumption A2, however, customers only use pure strategies. Denote by $\widehat{X}$ the announcement a customer receives and by $p(i \mid \widehat{X})$ the updated belief that a customer receiving the announcement $\widehat{X}$ is of type $i$ (where $i=A, B$ and $\widehat{X}=\widehat{A}, \widehat{B}$ ). The necessary condition for a customer at FI $A$, receiving a recommendation $\widehat{A}$, to buy product $A$ is then:

$$
p(A \mid \widehat{A}) R+(1-p(A \mid \widehat{A})) r-p_{A} \geq p(A \mid \widehat{A}) r+(1-p(A \mid \widehat{A})) R-p_{B}
$$

This can be simplified to

$$
(2 p(A \mid \widehat{A})-1) \Delta \geq p_{A}-p_{B}
$$

or equivalently,

$$
\Delta U_{A}(\widehat{A}) \equiv(2 p(A \mid \widehat{A})-1) \Delta-p_{A}+p_{B} \geq 0
$$


Correspondingly, the necessary condition for a customer at FI $A$, receiving a recommendation $\widehat{B}$, to buy product $B$ is:

$$
\Delta U_{A}(\widehat{B})=(2 p(B \mid \widehat{B})-1) \Delta-p_{B}+p_{A} \geq 0
$$

A Perfect Bayesian Equilibrium is then defined by a set of posterior beliefs $p(i \mid \widehat{X})$, which are consistent with the optimal behavior of FIs and customers as inferred from the signs of $\Delta \pi_{A}(A), \Delta \pi_{A}(B), \Delta U_{A}(\widehat{A})$ and $\Delta U_{A}(\widehat{B})$. The following lemma provides a characterization of the FIs' information revelation in equilibrium. It is the central result of our analysis.

Lemma 4 Under assumptions A1 and A2, equilibria in the information revelation game of FI A are as follows:

1. If $p_{A}<p_{B}-\Delta$, then FI $A$ truthfully reveals the customer's type and all customers purchase $A$.

2. If $p_{B}-\Delta<p_{A}<\rho$, then FI A truthfully reveals the customer's type and the customers purchase the good that matches their type.

3. If $\max \left[\rho, p_{B}-\Delta\right]<p_{A}<p_{B}+(2 q-1) \Delta$, then FI $A$ always announces $\hat{A}$ and customers purchase $A$.

4. If $p_{A}>p_{B}+(2 q-1) \Delta$, then either

(a) the FI A mixes its messages for both types of customers $(\alpha, \beta \in$ $(0,1) \times(0,1))$, or mixes its messages for one type of customer $(\alpha=1, \beta \in(0,1))$ or $(\beta=1, \alpha \in(0,1))$ within a range defined by $p_{A}>p_{B}+\Delta \max \left[2 \frac{\alpha q}{\alpha q+\beta(1-q)}-1,1-2 \frac{(1-\beta)(1-q)}{(1-\alpha) q+(1-\beta)(1-q)}\right]$ or

(b) systematically announces $\widehat{A}$ provided the out-of-equilibrium beliefs $P(B \mid \widehat{B})$ satisfy

$$
p_{A}>p_{B}+\Delta \max [2 q-1,1-2 P(B \mid \widehat{B})]
$$

or 
(c) systematically announces $\widehat{B}$ provided the out-of-equilibrium beliefs $P(A \mid \widehat{A})$ satisfy

$$
p_{A}>p_{B}+\Delta \max [2 q-1,2 P(A \mid \widehat{A})-1]
$$

and all customers purchase B.

5. If $p_{A}>p_{B}+\Delta$, then all customers purchase $B$ and any revelation strategy (including full revelation) is an equilibrium

The proof of the lemma is in the appendix. We can now use it to determine for a given set of parameters $\rho, q, \Delta$, and prices $p_{A}$ and $p_{B}$ what information revelation regime a firm is in. In one interval, $p_{B}+(2 q-1) \Delta<p_{A}<\rho$, there exist multiple equilibria: a fully revealing one where customers follow FI $A$ 's advice and many partially revealing equilibria in which all customers purchase product $B$. However, given that $p_{A}<\rho$, any partially revealing strategy by a sender type of FI $A$ (where sender types are "Knows customer is type $A$ " and "Knows customer is type $B$ ") is weakly dominated by a strategy of full revelation. Hence the partially revealing strategy will not survive any tiny trembles in the customer's decision, and we ignore it ${ }^{11}$. Since FI $A$ and FI $B$ are symmetric except for consumer's ex-ante preferences, we can replicate Lemma 2 for FI $B$ by substituting in $(1-q)$ for $q$.

In Figure 2 we fix $p_{B}$ and display FI $A$ 's information revelation regime for any possible $p_{A}$ that it may set. We find that when FI $A$ has very low prices, it has the incentives to reveal information truthfully and can capture the whole market. In contrast, when FI $A$ has high prices, it will not get any customers, and will be willing to say anything. For a middle range of prices, FI $A$ may credibly reveal information but only capture the customers who are good matches, or it may reveal nothing and take advantage of its ex-ante advantage in terms of consumers' preferences.

At this point we have solved the subgame of information revelation given fixed prices. We can now determine how each firm sets its prices and then determine which firm invests in information provision in equilibrium.

\footnotetext{
${ }^{11}$ More formally, type "Knows customer is type $A$ " gets a payoff of either 0 or $p_{A}$ by announcing $\hat{A}$ and gets a payoff of either 0 or $p_{A}-\rho$ by announcing $\hat{B}$. In the interval of parameters, $p_{A}<\rho$, so weak dominance is clear. Similarly type "Knows customer is type $B$ " gets a payoff of either 0 or $p_{A}$ by announcing $\hat{B}$ and gets a payoff of either 0 or $p_{A}-\rho$ by announcing $\hat{A}$. Therefore, any partially revealing equilibrium in this interval does not survive the test of trembling hand perfection.
} 


$$
\begin{aligned}
& 0 \leq \rho<p_{B}-\Delta
\end{aligned}
$$

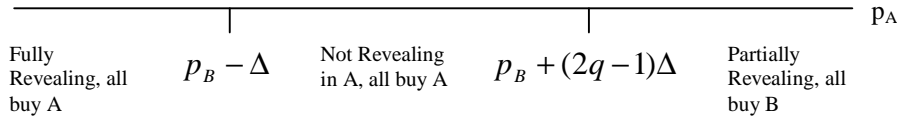

$$
\begin{aligned}
& p_{B}-\Delta \leq \rho<p_{B}+(2 q-1) \Delta \\
& \begin{array}{l|l|l|ll}
\hline & & & & p_{\mathrm{A}} \\
\begin{array}{l}
\text { Fully } \\
\text { Revealing, all } \\
\text { buy A }
\end{array} p_{B}-\Delta & \begin{array}{l}
\text { Fully } \\
\begin{array}{l}
\text { Revealing, } \\
\text { customers } \\
\text { follow advice }
\end{array}
\end{array} \rho \begin{array}{l}
\text { Not Revealing } \\
\text { in A, all buy A }
\end{array} p_{B}+(2 q-1) \Delta & \begin{array}{l}
\text { Partially } \\
\text { Revealing, all } \\
\text { buy B }
\end{array} \\
\end{array} \\
& p_{B}+(2 q-1) \Delta \leq \rho
\end{aligned}
$$

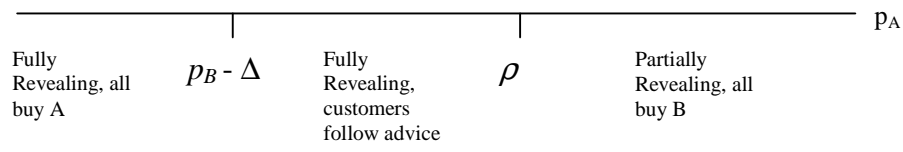

Figure 2: The Information Revelation Regimes of FI $A$ (holding $p_{B}$ fixed)

\subsubsection{The price competition game between specialized FIs}

The previous lemma characterizes a number of scenarios where there is either partial or no credible information disclosure, given $p_{A}$ and $p_{B}$. This limited information disclosure outcome is what one would expect to see in light of our observation that monopoly specialized FIs are never able to credibly convey information. We now show, however, that price competition among specialized FIs is likely to bring about equilibrium outcomes where each FI can credibly convey information. To see this, suppose for the sake of argument that specialized FIs are never able to credibly convey information. Then, as we showed earlier, Bertrand competition under no information will result in an equilibrium outcome where $\pi_{B}=0$ and $\pi_{A}=(2 q-1) \Delta$. But note that bank $B$ will then have a strict incentive to truthfully reveal the customer's type, as long as $\rho>0$. This is due to the fact that bank $B$ would be able to raise its price $p_{B}$ up to $\rho$, credibly convey information to its well matched customers and make higher profits.

In our formal analysis of the price competition stage game we begin by assuming that firm $A$ is the price leader and firm $B$ is the price follower. 
This means that FI $A$ essentially defines the choice set of possible information revelation regimes (with their accompanying profits) and FI $B$ decides where to locate in the choice set. Clearly this gives FI $B$ an advantage it never had when customers did not have access to information - it can force some information to be revealed credibly and increase its sales. Our simple observations above lead us to conclude:

Proposition 5 1) When $A$ invests in information and $B$ does not, there are two possible equilibria. If $\rho>(2 q-1) \Delta$, equilibrium is $p_{A}=\rho, p_{B}=\rho+\Delta$, all customers approach FI $A$ and are revealed their true types. Customers then purchase at the bank that matches their type, so profits are $\pi_{A}=q \rho$, $\pi_{B}=(1-q)(\rho+\Delta)$. If $\rho<(2 q-1) \Delta$, equilibrium is $p_{A}=(2 q-1) \Delta, p_{B}$ undetermined, all customers approach FI $A$, are all told they are type $A$, and purchase at FI A. Profits are $\pi_{A}=(2 q-1) \Delta, \pi_{B}=0$.

2) When $B$ invests in information and $A$ does not, the equilibrium is $p_{A}=\min [(1-q) \rho+\Delta, \rho+(2 q-1) \Delta], p_{B}=\rho$, all customers approach $F I B$ and are revealed their true types. Customers follow the advice of FI $B$ and profits are $\pi_{A}=q p_{A}, \pi_{B}=(1-q) \rho$.

3) When both $A$ and $B$ invest in information, the equilibrium is $p_{A}=$ $\min [(1-q) \rho+\Delta, \rho+(2 q-1) \Delta], p_{B}=\rho$, just as in the case of only $B$ investing in information. All customers approach FI B or are indifferent between approaching FI $A$ or FI B and are revealed their true types. Customers follow the advice of the bank they approach and profits are $\pi_{A}=q p_{A}, \pi_{B}=(1-q) \rho$.

The proof is in the appendix. Thus, for almost all of the cases the types of customers are completely revealed, and prices are such that they purchase the product which matches their type. This results from the following intuition: FI $B$ can almost always set its price low enough so that FI $A$ will have zero profits. Therefore FI $A$ must set its price such that FI $B$ will find it more attractive not to undercut. This must be a regime where both FI $A$ and FI $B$ make positive profits. The only area where both firms may profit is where they can commit to fully revealing types and customers find the price differential small enough to purchase the product which matches their type. The only case in which information is not revealed occurs when ex-ante valuations are so biased towards product $A((2 q-1) \Delta>\rho)$ that FI $A$ can extract higher rents by not revealing information. The role of reputation is quite critical here - in order to commit to full revelation, the payoff from deviating must be non-positive, but the size of $\rho$ strictly limits the payoff for the firm that is providing information. 


\subsubsection{The information provision game between specialized FIs}

We are now in a position to roll back to the first stage of the game, where FIs make their investment in information-provision decisions. We have so far taken the information structure as given (which bank provides information). Now we let banks choose whether they want to invest in an information provision technology (hire analysts, build IT systems, etc.) at some fixed ${ }^{12}$ cost $f>0$. To the extent that information provision is a public good and is costly to produce it is efficient for at most one bank to provide this information. We now show that in equilibrium no more than one bank will provide information, and that it is the disadvantaged bank (i.e. FI $B$ ) that is likely to provide that information. This follows from the fact that the disadvantaged bank is the one with the strongest incentives towards truthful revelation of information. Consequently, we are able to obtain the remarkable result that, as long as investment in information provision is profitable in equilibrium, there always will be full information disclosure under competition between specialized FIs.

The basic logic leading us to this conclusion runs as follows. Under no information provision, the unique equilibrium in profits is such that $\pi_{B}=0$ and $\pi_{A}=(2 q-1) \Delta$. If bank $A$ were to provide information and communicate it credibly to its customers it would have to set its margin $p_{A}$ no higher than $\rho$. Thus, bank $A$ 's profits under full credible information revelation would be no more than $q \rho-f$. Therefore bank $A$ would not want to provide information whenever $(2 q-1) \Delta \geq q \rho-f$. Proposition 5 also states that when $(2 q-1) \Delta \geq \rho$ and only bank $A$ is in a position to provide information then there will be no credible information disclosure in equilibrium. This appears to set a limit to the amount of credible information disclosure we should expect to see in an equilibrium with competition among specialized FIs.

However, since bank $B$ has, if anything, even more to gain from providing information there will be full credible information disclosure in equilibrium for a much larger set of parameter values.

\footnotetext{
${ }^{12}$ If instead we assumed that there was a constant marginal cost per customer, the results would be qualitatively the same. Examining a game where the FIs only inform a fraction of their customers (i.e. if they randomize or have a convex cost function) is outside the scope of the paper.
} 
Proposition 6 There is full credible information disclosure in pure strategy equilibria when $\rho \geq \frac{f}{1-q}$.

i) For $\rho$ small $\left(\frac{f}{1-q}<\rho<\frac{(2 q-1) \Delta+f}{q}\right)$ there is a unique equilibrium where $F I B$ provides information and FI $A$ does not.

ii) For $\rho$ large $\left(\rho>\frac{(2 q-1) \Delta+f}{q}\right)$ three equilibria coexist, one where only FI A provides information, one where only FI $B$ provides information and a mixed strategy equilibrium.

Otherwise, for $\rho<\frac{f}{1-q}$ no information will be disclosed.

The decision to invest is derived from a two-by-two game summarized by the following matrix ${ }^{13}$ :

\section{FI B}

\begin{tabular}{|c|c|c|c|}
\hline \multirow{4}{*}{ FI A } & & No Info & Info \\
\hline & No Info & $(2 q-1) \Delta, 0$ & $q p_{A^{\prime}}(1-q) \rho-f$ \\
\hline & Info if $\rho>(2 q-1) \Delta$ & $q \rho-f,(1-q)(\rho+\Delta)$ & $q p_{A}-f,(1-q) \rho-f$ \\
\hline & Info if $\rho<(2 q-1) \Delta$ & $(2 q-1) \Delta-(1-q) \rho-f, 0$ & $q p_{A}-f,(1-q) \rho-f$ \\
\hline
\end{tabular}

Matrix for Competition among Specialized Banks (A is the price leader)

FI $B$ has a strong incentive to provide information since the information gives it the market power it was lacking when all customers ex-ante preferred product $A$. FI $A$ can free ride on this information provision as its own investment in information would not change its returns. In fact, for intermediate values of $\rho$, FI $A$ has a dominant strategy not to provide information since if FI $B$ doesn't provide information FI $A$ can still enjoy its inherent advantage. Once $\rho$ gets larger, FI $A$ can possibly credibly provide information, because it receives a high enough rent to justify its provision. Lastly, notice that as $\rho$ approaches zero, all of FI $B$ 's rents disappear in every scenario. The lack of a reputation cost eliminates the ability to credibly reveal information, which FI $B$ used to achieve positive profits.

Total welfare is maximized in the equilibria where full information is provided, since each customer is able to realize more utility due to the match.

\footnotetext{
${ }^{13}$ For presentation purposes, we place a strict upper bound such that $f<(1-q)(2 q-1) \Delta$. This incorporates the case where the fixed cost is close to zero.
} 
When information is not provided, as is the case when $\rho$ is tiny, matching efficiency is not realized and welfare decreases.

When FI $B$ is the price leader, the qualitative results do not change substantially. The payoffs are given by the following matrix (the proof is in the appendix):

FI B

\begin{tabular}{|c|c|c|}
\hline & No Info & Info \\
\hline No Info & $(2 q-1) \Delta+p_{B}{ }^{N I, N I}, 0$ & $q(\rho+\Delta),(1-q) \rho-f$ \\
\hline Info if $\rho>(2 q-1) \Delta$ & $q \rho-f,(1-q)(\rho-(2 q-1) \Delta)$ & $q(\rho+\Delta)-f,(1-q) \rho-f$ \\
\hline Info if $\rho<(2 q-1) \Delta$ & $(2 q-1) \Delta-(1-q) \rho+p_{B}^{I, N I}-f, 0$ & $q(\rho+\Delta)-f,(1-q) \rho-f$ \\
\hline
\end{tabular}

Matrix for Competition among Specialized Banks (B is the price leader)

A few comments are in order regarding the case where FI $B$ is the price leader. First, the (No Information, No Information) and the (Information if $\rho<(2 q-1) \Delta$, No Information) cases are now partially undetermined, since for any $p_{B}$ announced by FI $B$, FI $A$ will be able to grab all of the customers and leave FI $B$ with zero profits. For the purposes of comparison, we assume $p_{B}$ is the same in both cases $\left(p_{B}^{N I, N I}=p_{B}^{N I, I}\right)$. Second, the (Information, Information) case is more complex here, since FI $A$ 's advantage in ex-ante preferences $\left(q>\frac{1}{2}\right)$ allows it to free ride on FI $B$ in the sense that FI $A$ may keep its prices high and force FI $B$ to inform customers of their types. Indeed, the equilibrium has FI $A$ partially revealing, FI $B$ fully revealing, all customers approaching FI $B$ first and then following FI $B$ 's advice.

Third, it is clear from the (Information, Information) case, and the (No Information, Information) case that FI $A$ is able to exploit its role as a price follower to its advantage in achieving higher payoffs.

Finally, we find again that for reputation cost that is tiny or equal to zero $\left(\rho<\frac{f}{1-q}\right)$, the unique equilibrium is that neither firm provides information. For larger reputation costs, the unique equilibrium is that only FI $B$ provides information. All customers go to FI $B$, are revealed their true type, and 
purchase the product which matches their type. Thus, contrasting with the case where $A$ is price leader, there is no multiplicity of equilibria here for large values of $\rho$.

\section{Competition between a one-stop bank and a specialized FI}

In this section we consider competition between a one-stop bank, FI 1, and another FI that remains specialized and offers, say, product $B$. Since both banks now offer product $B$, competition is tougher in a certain sense. We begin with the case where FI 1 is the price leader.

\subsection{Price leadership by FI 1}

When neither FI provides any information zero profits are made on product $B$ in equilibrium. Equilibrium profits are then the same as under competition between specialized FIs. Similarly, the equilibrium under full information (i.e. where customers know their type) is also identical to that of competition between specialized FIs. The reason for this is that since $B$ plays last, it will undercut FI 1 . Hence, the power of FI 1 to set a lower price for product $B$ brings no additional advantage - the one-stop bank does not profit strategically or directly from having product $B$.

When FI $B$ can provide information to customers, however, FI 1 can set the price $p_{1 B}$ strategically to force FI $B$ into an information revelation regime that is favorable to FI 1 . This is the main difference between competition among specialized FIs $A$ and $B$, and competition between a one-stop bank FI 1 and a specialized FI $B$ when information provision is possible. Therefore, FI 1's profit here is at least as high, if not higher, than the profits of FI $A$ in the case of competition among specialized banks ${ }^{14}$. Recall that in section 4.3.3, we found that $p_{A}=\min [(1-q) \rho+\Delta, \rho+(2 q-1) \Delta]$ in the equilibrium where FI $B$ provides information. In this equilibrium FI $A$ has to set $p_{A}$ low enough to make sure that FI $B$ would not lower its price in an attempt to grab the whole market. Now, the one-stop bank can discipline FI $B$ by setting its price for product $B$ appropriately and is free to set $p_{1 A}=(1-q) \rho+\Delta$. Hence, FI 1 is able to generate higher profits $\pi_{1}=q((1-q) \rho+\Delta)$ in this

\footnotetext{
${ }^{14}$ As summarized in the first payoff matrix of section 4.3.3.
} 
case. In the cases where FI B does not provide information, though, FI $B$ can undercut FI $A$ on product $B$, making the solutions exactly the same as when specialized FIs compete.

\subsection{Price leadership by FI B}

In contrast, when FI $B$ is the price leader, results change in the information revelation game from when there were just two specialized banks competing. Let's assume that FI $B$ chooses some price $p_{B}$.

In the environment where no information is provided, the equilibrium is $p_{1 A}=\min \left[(2 q-1) \Delta+p_{B}, q R+(1-q) r\right]$ and $p_{1 B}>p_{B}$, with all profits going to the one-stop bank and all consumers purchasing product $A$. This solution is the same as when competition is among specialized FIs.

If instead customers know their type ex-ante, the one stop bank gets all of the profits and consumers purchase the product which matches their type ${ }^{15}$. Here, the one-stop bank directly steals clientele from FI $B$ by undercutting it on product $B$. This diverges from the specialized FI solution since the one-stop bank can't be given an incentive to split the customer base.

When FI 1 decides whether to provide information, the signaling game changes significantly from section 4 . First of all, the game for FI 1 can look like the game where a one-stop bank has no competition if it undercuts FI $B$, setting $p_{1 B}=p_{B}-\delta$ (where $\delta$ is small). In this case we can apply the results from the signaling game of Proposition 2 to find the solution. It is straightforward to show that if FI 1 undercuts FI $B$, it will set $p_{1 A}=$ $p_{1 B}+\rho=p_{B}-\delta+\rho$ and achieve profits of $p_{B}-\delta+q \rho$ when $\rho>(2 q-1) \Delta$, or set $p_{1 A}=p_{1 B}+(2 q-1) \Delta=p_{B}-\delta+(2 q-1) \Delta$ and achieve profits of $p_{B}-\delta+(2 q-1) \Delta-(1-q) \rho$ when $\rho<(2 q-1) \Delta$. This gives FI 1 weakly larger profits than a specialized FI $A$ gets when FI $B$ does not provide information (compare with Figure 4).

When FI $B$ provides information, however, it may choose $p_{B}$ strategically to avoid undercutting behavior and make positive profits. Basically, it can choose $p_{B}^{*}$ such that it satisfies the incentive constraint of FI 1 to prefer not to undercut on product $B$. Using this logic and the solution from the case of competition among specialized banks FI $A$ and FI $B^{16}$, this implies that

\footnotetext{
${ }^{15}$ Restricting attention to pure strategies, if $p_{B}>r, p_{1 A}=R$ and $p_{1 B}=p_{B}-\delta$ (where $\delta$ is small), while if $p_{B}<r, p_{1 A}=\Delta+p_{B}-\delta$ and $p_{1 B}=p_{B}-\delta$.

${ }^{16}$ Note that in this case, one part of the no-undercutting constraint is that $\rho<p_{1 A}-$ $(2 q-1) \Delta$. This implies $(1-(1-q)(2 q-1)) \Delta>\rho$, which we assume to be true here.
} 
$p_{B}^{*}=\min \left[\rho, \frac{q}{1-q}(\Delta-\rho)\right]$ if FI 1 provides information and $\rho>(2 q-1) \Delta$, and $p_{B}^{*}=\rho$ otherwise. This yields the following payoff matrix:

FI B

\begin{tabular}{|c|c|c|}
\cline { 2 - 3 } \multicolumn{1}{c|}{} & No Info & Info \\
\hline FI A & $(2 q-1) \Delta+p_{B}{ }^{N I, N I}, 0$ & $q(\rho+\Delta),(1-q) \rho-f$ \\
\hline Info if $\rho>(2 q-1) \Delta$ & $p_{B}{ }^{I, N I}+q \rho-f, 0$ & $q\left(p_{B}{ }^{*}+\Delta\right)-f,(1-q) p_{B}{ }^{*}-f$ \\
\hline Info if $\rho<(2 q-1) \Delta$ & $(2 q-1) \Delta-(1-q) \rho+p_{B}^{I, N I}-f, 0$ & $q(\rho+\Delta)-f,(1-q) \rho-f$ \\
\hline
\end{tabular}

Matrix for Competition between a One-Stop and a Specialized FI (B is the price leader)

Despite the differences in the potential strategies, we find equilibria that are similar to our previous ones ${ }^{17}$. For $\rho<\frac{f}{1-q}$, the unique solution is that neither FI provides information. For larger values of $\rho$, there may either be one equilibrium, where only FI $B$ provides information, or three equilibria, two pure strategy equilibria where only one FI provides information and one mixed strategy equilibrium ${ }^{18}$.

\section{Market Structure}

We are now in a position to explore the incentives for a specialized bank to expand its activities and become a one-stop bank and to analyze the welfare implications of such a move. The conditions under which one-stop banks can prosper are quite interesting given current trends. The abolition of the

\footnotetext{
${ }^{17}$ Also assuming that $p_{B}^{N I, N I}=p_{B}^{I}, N I$ as before.

${ }^{18}$ Specifically, if $\rho<q \Delta$, there is only one equilibrium in the high range (FI $B$ provides information). If $\rho>q \Delta$, for $\frac{f}{1-q}<\rho<\hat{\rho}$, there is only one equilibrium (FI $B$ provides information), while for $\rho>\hat{\rho}$ there are three equilibria (one where only FI $B$ provides information, one where only FI $A$ provides information, and one where both FIs mix their strategies). Here we define $\hat{\rho}=\max \left[\frac{(2 q-1) \Delta+f}{q}, \frac{q \Delta-f}{q}\right]$.
} 
Glass-Steagall act in 1999 paved the way in the United States for the creation of one-stop banks. In Europe, such banks, called "universal banks" have existed for many years, but are now undergoing a shake-up as mergers across borders are seen as necessary for survival ${ }^{19}$. The traditional explanation for the trend towards consolidation relates to the economies of scope realized by selling multiple financial products from the same outlet. However, by analyzing these banks from an information provision perspective, we open up a richer understanding of market structure ${ }^{20}$.

Our analysis points out that the gains from merger are largest when reputation costs are very low. For very small costs of reputation, no information is provided when specialized banks compete, as the benefits of information disclosure do not cover the cost. However, when the market is dominated by a one-stop bank, advice can be credibly provided even if the bank extracts most of the customers' value of information. For higher reputation costs this comparative advantage of one-stop banks is eroded, as specialized banks are also able to give advice credibly.

A specialized bank that is competing against another specialized bank may decide that instead of trying to merge with its competitor, it could extend its product line. Clearly, this would soften competition if the market is already homogeneous (such as competition between two FI $B \mathrm{~s}$ ). However, another product can also be used as a strategic buffer, keeping the other firm from entering a disadvantageous information revelation regime and therefore allowing more profits (we see this when the reputation cost is low $\left(\rho<\frac{2(1-q)}{q} \Delta\right)$ in competition between FI 1 and FI $\left.B\right)$. Lastly, a monopoly specialized bank would gain substantially by turning itself into a multi-product bank, since this would allow it to raise spreads even more while resolving the fundamental conflict of interest problem it faces in giving advice.

From a welfare perspective, when customers are ex-ante fully informed, welfare is maximized under a one-stop bank, but at the expense of consumer surplus. When customers are uninformed, welfare is low as all $B$ types purchase product $A$. Endogenizing information revelation comes close to maximizing welfare (within the cost $f$ of information provision) at the

\footnotetext{
${ }^{19}$ This is echoed in Banking Surveys by The Economist (April 4, 2002) and The Financial Times (May 24, 2002).

${ }^{20}$ We also note that the traditional use of the term "conflict of interest" in the context of one-stop banks refers to the underwriting of securities to subsidize bad loans; we do not consider this issue, instead focusing on information provision.
} 
expense of lower firm profits due to competitive pressure. Market power due to conglomeration restores full extraction of the maximized surplus by the FI when information revelation is possible ${ }^{21}$.

Although we do not model heterogeneity among clients, it is likely that larger and wealthier customers have more information about (or more advisers to counsel them on) their specific needs. Interestingly, by being better informed, they could be forced to pay more in terms of higher prices per product. These types of clients may be large money-makers for banks in terms of not only volume, but per-unit return. Indeed, there is a large focus in the banking industry on catering to these higher end customers ('private banking'). We elaborate on the effect that we describe here in the next section.

\section{Unobservable Investments in Information Provision}

In the previous sections we have assumed that customers were able to verify that the bank had made the necessary investment to provide them with reliable information. However, these investments may be difficult to verify in reality. When that is the case, banks' investments in information provision are subject to moral hazard. Banks will invest in information provision if and only if this leads to higher profits, while customers will only infer the investment has been made when the bank profits from the investment. As a consequence, the nature of the equilibrium is modified.

A natural question that then arises is what impact the observability of information provision services has on the industry. This question becomes even more salient when we discuss the nature of Independent Financial Advisors, advisors separate from banks who may or may not be providing "good" information.

\footnotetext{
${ }^{21}$ How realistic is the notion of market power among financial intermediaries? "A handful of familiar names - Citigroup, J.P. Morgan Chase, Goldman Sachs, Merrill Lynch dominates these businesses, either because it takes a huge investment to build them, or because only top names are trusted. Yet only Citigroup offers corporate and institutional clients the full range of services..." (The Economist, April 4th, 2002)
} 


\subsection{Unobservable investments with competition between specialized FIs}

The basic timing of the game remains the same, except that the investment in stage 1 in information provision is observable only to the firm making the investment. The values of all parameters of the game are common knowledge among all participants. For brevity, we will only focus on the case of competition between specialized banks where FI $A$ is the price leader.

Consider the equilibrium where FI $B$ invests in information acquisition at cost $f$ and provides advice to all customers. If investment is unobservable, FI $B$ may find that it is more profitable to save on the cost $f$ by not investing in information acquisition and to just make uninformed recommendations. In this situation, to make sure that FI $B$ does have the right incentive to invest in information acquisition, the following incentive constraint must hold:

$$
(1-q) p_{B}-f>p_{B}-q \rho
$$

To understand this constraint, note that the highest payoff FI $B$ can get by deviating and giving uninformed advice is to simply always recommend product $B$ (since the beliefs of customers are held fixed). In that case it always sells product $B$ at price $p_{B}$ but also pays a reputation cost on the fraction $q$ of $A$-type customers. On the other hand, if FI $B$ does invest in information it is able to recommend product $B$ only to well-matched customers and thus avoid paying a reputation cost for poor advice. This incentive constraint puts an upper bound on $p_{B}$ of $\rho-\frac{f}{q}$. Notice that this is strictly lower than the upper bound for credible information provision when investment in information is observable $(\rho)$. Adding the participation constraint:

$$
(1-q) p_{B}-f>0
$$

and setting $p_{B}$ equal to its upper bound $\rho-\frac{f}{q}$, then requires that:

$$
\rho>\frac{f}{(1-q) q}
$$

for information provision to be credible in equilibrium. This condition on the reputation cost is strong. In particular, in the interval for $\rho,\left(\frac{f}{(1-q)}, \frac{f}{(1-q) q}\right)$, information would be provided when investment is observable but would not under unobservable investment. 
Similarly, in equilibria where FI $A$ is providing information we can derive an incentive constraint for FI $A$ by substituting $1-q$ for $q$ in equation 6 and set FI $A$ 's price equal to the maximum of this interval, $\rho-\frac{f}{1-q}$. The participation constraint for FI $A$ is not symmetric, however, since FI $A$ 's payoff from not investing in information is positive: $(2 q-1) \Delta$. Thus the participation constraint reduces to:

$$
q p_{A}-f>(2 q-1) \Delta \quad \Longrightarrow \rho>\frac{f}{(1-q) q}+\frac{(2 q-1) \Delta}{q}
$$

As in the case of observable investment, an equilibrium that has FI $A$ investing in information only occurs for higher reputation costs $\rho$. It is also clear that the cutoff for which there are equilibrium where either FI $A$ or FI $B$ provide information is higher here than in the case of observable investment (where it was $\frac{f}{q}+\frac{(2 q-1) \Delta}{q}$ ).

Note also that now there is always an equilibrium where no firm invests in information. This is clear when we look at the incentive constraint. If the FI does not invest in information and the customers know this, it gets some non-negative payoff $\tilde{\pi}$. By deviating and investing in information, given that customers believe it will not provide any, its payoff will be $\tilde{\pi}-f$. We call this the "Cassandra effect", as the FI may have valuable information to reveal, but no customer is listening.

In sum, the set of equilibria resembles that for observable information acquisition with two main differences. First, there is a larger interval for which no information provision is the unique equilibrium. Second, due to the "Cassandra effect", no information provision is always an equilibrium.

\subsection{Independent Financial Advisors}

In the negotiations leading up to the $\$ 1.4$ billion settlement between Wall Street investment banks and Elliot Spitzer and the SEC, an important proposal for resolving conflicts of interest of "sell-side" analysts in investment banks was the creation of a fully independent research entity that would employ these analysts. Although this idea was eventually shelved, separating financial advice from the sale of financial products seems like a simple and appealing remedy to address the kinds of conflicts of interest we have considered so far. Two forms of separation may be envisioned: a limited form within each bank that sets up so-called "Chinese walls" between the analysts and the sales people, or the more radical form, which would involve 
spinning off in-house financial analysts into full-fledged independent financial advisors (IFAs) ${ }^{22}$. So far, only the former type of separation is required, although the "Chinese walls" that have been in place all along (but probably had been easily circumvented by meetings in Chinese Restaurants) have now been significantly tightened under the Sarbanes-Oxley Act.

Some of the key issues in the negotiations with Elliot Spitzer concerned the quality of financial advice under an independent entity, analysts' incentives to do the necessary research, and the form of their compensation. It turns out that our analysis here can shed light on these core issues ${ }^{23}$. In particular, in our model the separation of analysts into IFAs can be strictly beneficial to the financial intermediaries. In addition, as we now illustrate, it is generally easier to create incentives for IFAs to acquire costly information and to credibly provide advice than for in-house analysts. As in the previous section, we limit our focus to the case of competition between two differentiated specialized banks.

The fact that financial intermediaries will benefit from credible information provision by IFAs is easy to see. Suppose that the financial advisor has the correct incentives to tell the truth ${ }^{24}$. Then customers have perfect information before they approach the banks. As shown earlier in the paper, when competition exists between specialized banks, profits are larger under full information than when information must be provided by the banks directly. The banks charge lower prices when they must provide their own information in order to credibly convey that information. In either case, total surplus is the same, since all customers match perfectly, although consumer surplus is clearly lower when financial advice is delivered separately.

To see why IFAs have better incentives for information acquisition note

\footnotetext{
${ }^{22}$ We specifically define IFAs as advisory firms which don't sell financial products; in the UK, IFAs may sell financial products (their independence is defined by not being owned by a financial product provider). Interestingly enough, a study by the UK's Financial Service Authority and Charles River Associates (2001) found that "There is significant bias in the advice" of these types of financial advisors on some of the products they sell.

${ }^{23}$ The type of conflict of interest in the SEC case are not exactly of the type that we model here. We attempt to give insight into some of the similar issues that arise.

${ }^{24}$ This can be easily accomplished if the independent financial advisor charges a fixed amount for each customer, but suffers a positive reputation cost if she lies. Alternatively, the advisor may be paid a fixed amount irrespective of the number of customers by an FI, but still suffer some reputation cost (such as firing when customers complain), and the results will go through.
} 
that the incentive constraint ${ }^{25}$ for IFAs is given by:

$$
\rho_{I}>\frac{f}{1-q}
$$

where $\rho_{I}$ is the reputation cost of the IFA. Indeed, if the IFA does not invest in information it saves $f$ but it incurs a reputation cost of $\rho_{I}(1-q)$. If $\rho_{I}=\rho$, we thus observe that the IFAs will provide information for the same range of parameters as specialized banks with observable investments. The IFAs will provide information in some cases when specialized banks with unobservable investments do not, namely $\rho \in\left(\frac{f}{(1-q)}, \frac{f}{(1-q) q}\right)$. In this case, IFAs help the specialized banks by revealing information where the banks couldn't, as well as allowing the banks to extract more rents. As a caveat, however, the reputation cost $\rho_{I}$ may arguably be less than $\rho$, due to the fact that there is much less at stake in a continuing relationship between an IFA and a customer. This could reduce the provision of information by IFAs relative to specialized banks. We also note that for all parameter values there exists a "Cassandra effect" equilibrium where the IFA does not invest in information, as before.

\section{Conclusion}

This paper considers several aspects of market structure from the perspective of information provision to customers. By using this alternative road we obtain a new perspective on conflicts of interest and consolidation in the banking industry. We have found that competition fosters information provision when reputation costs are present. The fact that a specialized FI has incentives to provide information may surprise, since it will always lose to its competitor the customers that are not of its type. Still, if we consider as the starting point a situation where absent information a FI will get no customers, providing information appears as an additional tool in the competition for market share.

We have also found that the gains from increasing the number of financial products offered and becoming a one-stop bank are largest when market power can be exerted or customers have switching costs. Without these built

\footnotetext{
${ }^{25}$ In the constraint, we implicitly assume the type of fixed amount per customer compensation scheme mentioned in the previous footnote.
} 
in customer bases, competition erodes the profit margins for information revelation. Finally, financial intermediaries may actually have an incentive to separate advice from sales as it could allow them to differentiate their products and receive higher margins.

It would be interesting to extend this line of research in a dynamic direction in order to quantify the potential reputation costs that banks may incur. Another aspect that is worth further examination is allowing for heterogeneity in customer's knowledge of their types. With the advent of the internet and private banking, it is probable that certain clients have better information about which investments best match their needs. Our results in this context suggest that if customers have more information, market power and rents can actually increase, making this topic quite relevant to policy discussions.

\section{References}

Benabou, Roland and Laroque, Guy. (1992), "Using Privileged Information to Manipulate Markets: Insiders, Gurus, and Credibility", Quarterly Journal of Economics, 107, 921-958.

Bester, Helmut. (1998), "Quality Uncertainty Mitigates Product Differentiation", RAND Journal of Economics, 29:4, 828-844.

Cho, In-Koo and Kreps, David (1986), "Signaling Games and Stable Equilibria", Quarterly Journal of Economics, 102, 179-221.

Darby, M.R. and Edi Karni (1973) "Free Competition and the Optimal Amount of Fraud." Journal of Law and Economics, Vol. 16, pp. 67-88.

Demski, Joel and David Sappington (1987), "Delegated Expertise." Journal of Accounting Research, Vol. 25, pp. 68-89.

The Economist (April 4th, 2002), "Big, Bigger, Biggest", The Economist.

Emons, Winand. (1997), "Credence Goods and Fraudulent Experts", Rand Journal of Economics 28, 107-119.

Emons, Winand. (2001), "Credence Goods Monopolists", International Journal of Industrial Organization, 19, 375-389.

Garicano, Luis and Tano Santos (2004), "Referrals", American Economic Review (forthcoming)

Grossman, S. J., and O. D. Hart (1980): "Disclosure Laws and Takeover Bids," Journal of Finance, 35, 323-34. 
Hotelling, Harold. (1929), "Stability in Competition", Economic Journal, 39, 41-57.

Judd, Kenneth L. (1985), "Credible Spatial Preemption", RAND Journal of Economics, 16:2, 153-66.

Laslett, Robert, Wilsdon, Tim, and Malcolm, Kyla. (2001) "The effect of commission based remuneration on financial advice", Financial Service Authority website (http://www.fsa.gov.uk/pubs/other/pol_res1.pdf).

Mailath, George. (1989), "Simultaneous Signaling in an Oligopoly Model", Quarterly Journal of Economics, 104:2, 417-427.

Meurer, Michael, and Stahl, Dale O. (1994), "Informative Advertising and Product Match", International Journal of Industrial Organization, 12, $1-19$.

Milgrom, Paul and John Roberts. (1982), "Limit Pricing and Entry under Incomplete Information: An Equilibrium Analysis", Econometrica, 50:2, 443460 .

Milgrom, Paul and John Roberts. (1986), "Relying on the Information of Interested Parties", RAND Journal of Economics, 17, 18-32.

Morgan, John and Stocken, Phillip C. (2003), "An Analysis of Stock Recommendations", RAND Journal of Economics, 34, 183-203.

Okuno-Fujiwara, Masahiro, Postlewaite, Andrew and Suzumura, Kotaro. (1990), "Strategic Information Revelation", Review of Economic Studies, $57: 1,25-47$.

Pesendorfer, Wolfgang and Wolinsky, Asher. (2003), "Second Opinions and Price Competition: Inefficiency in the Market for Expert Advice", Review of Economic Studies, forthcoming.

Pitchik, Carolyn and Schotter, Andrew. (1987), "Honesty in a Model of Strategic Information Transmission", American Economic Review, 77:5, 1032-1036.

Riley, John G. (2001), " Silver Signals: Twenty-Five Years of Screening and Signaling ", Journal of Economic Literature, 39:2, 432-478.

Saigol, Lina, and Thal Larsen, Peter. (May 24, 2002), "Banks Widen Horizons in Search For Right Targets", The Financial Times.

Shaked, Avner and Sutton, John. (1983), "Natural Oligopolies", Econometrica, 51:5, 1469-1484.

Shavell, Steven. (1994), "Acquisition and disclosure of information prior to sale", RAND Journal of Economics, 25:1, 20-36.

White, Ben. (April 30, 2003), "On Wall Street, Stock Doublespeak", washingtonpost.com. 
Wolinsky, Asher. "Competition in a Market for Informed Experts' Services." Rand Journal of Economics, Autumn 1993, 24(3), pp.380-398.

\section{Mathematical Appendix}

\subsection{Monopoly Banking}

\subsubsection{Specialized Monopoly (Proposition 1)}

We first examine the case of a monopoly specialized in product $A$. If the customer does not purchase at FI $A$, he receives a utility of zero and the bank makes zero profits. FI $A$ can make two statements, "recommend product $A$ " $(\hat{A})$ and "don't recommend product $A$ " $(\sim \hat{A})$. Lying when the customer purchases the product costs the FI $\rho$ per customer. Note that this proof is quite similar (though simpler) to that of the competing specialized banks, which we analyze in detail in the next section. Hence we only sketch the proof here. We consider only pure strategies for the customers, using assumption A2.

- It can never be that customers who hear $\hat{A}$ choose $\sim A$ and customers who hear $\sim \hat{A}$ choose $A$. If $p_{A}>\rho$, then the FI would announce $\sim \hat{A}$ always. By the Cho-Kreps intuitive criterion, the probability of hearing $\hat{A}$ given type $\sim A(P(\hat{A} \mid \sim A))$ equals zero. Hence, a customer who hears $\hat{A}$ will always choose $A$ and type $A$ would deviate since $p_{A} \leq R$. If $p_{A}<\rho$, there should be full revelation, but then upon hearing $\hat{A}$, the customer prefers $A$.

- When customers who hear $\hat{A}$ choose $A$ and customers who hear $\sim \hat{A}$ choose $\sim A$, then if $p_{A}<\rho$ the FI will fully reveal. However, since $\rho<r$ from $\mathbf{A 1}$, a customer hearing $\sim \hat{A}$ will always choose $A$ and there is no equilibrium. When $p_{A}>\rho$, the equilibrium will be non-revealing, with the additional requirements that $p_{A}<q R+(1-q) r$ and (using Cho-Kreps) $p_{A}>r$.

- When customers who hear $\hat{A}$ choose $A$ and customers who hear $\sim \hat{A}$ choose $A$, there is a fully revealing equilibrium when $p_{A}<r$.

- Lastly, when customers who hear $\hat{A}$ choose $\sim A$ and customers who hear $\sim \hat{A}$ choose $\sim A$, we have partially revealing equilibria (where 
type $A$ and type $\sim A$ mix their strategies). These are possible when $p_{A}>\max [r+P(A \mid \hat{A}) \Delta, r+P(A \mid \sim \hat{A}) \Delta]$. The minimum of this maximum is $q R+(1-q) r$ (we derive a very similar result in the proof of Lemma 4 below).

The results of the signaling game give us a profit function for every possible value of $p_{A}$. It is easy to see that there are two possible prices that could maximize the FI's profit: $p_{A}=r$ which yields $\pi_{A}=r$ and $p_{A}=q R+(1-q) r$ which yields $\pi_{A}=r+q \Delta-(1-q) \rho$. Hence, since $q>\frac{1}{2}$, the highest profits result when FI $A$ sets $p_{A}=q R+(1-q) r$ and does not reveal any information.

The signaling game for a monopoly FI $B$ is exactly the same, except that $1-q$ should be substituted for $q$. Hence, there are two possible prices that could maximize the FI's profit: $p_{A}=r$ which yields $\pi_{A}=r$ and $p_{A}=$ $(1-q) R+q r$ which yields $\pi_{A}=r+(1-q) \Delta-q \rho$. FI $B$ chooses the latter price when the reputation cost is not too high, $\rho<\frac{1-q}{q} \Delta$.

\subsubsection{One-stop Monopoly (Proposition 2)}

When information revelation is possible, the one-stop bank engages in a signaling game in which it can recommend product $A$ or product $B$. The reputation cost $\rho$ is incurred when the one-stop bank lies to the customer and the customer makes a purchase (of either product). Again, since this proof is quite similar to the one above and to the competing specialized bank proof (which we go over in detail), we only summarize the main points.

First, there can never be any equilibrium where customers who hear $\hat{A}$ choose $B$ and customers who hear $\hat{B}$ choose $A$. When customers who hear $\hat{A}$ choose $A$ and customers who hear $\hat{B}$ choose $A$, there is a fully revealing equilibrium where $p_{A}-p_{B}<-\Delta$. When customers who hear $\hat{A}$ choose $B$ and customers who hear $\hat{B}$ choose $B$, there is a fully revealing equilibrium where $p_{A}-p_{B}>\Delta$. Finally, when customers who hear $\hat{A}$ choose $A$ and customers who hear $\hat{B}$ choose $B$, there are two ranges of equilibria ${ }^{26}$ : when $-\rho<p_{A}-p_{B}<\rho$ the equilibrium is fully revealing and if $\rho<(2 q-1) \Delta$,

\footnotetext{
${ }^{26}$ Note that there doesn't exist an information revelation equilibrium for certain parameter values because we don't allow for mixed strategies on the part of customers here due to Assumption 2. If the FI set prices in these regions $\left(-\Delta<p_{A}-p_{B}<-\rho\right.$ and $\left.\max [\rho,(2 q-1) \Delta]<p_{A}-p_{B}<\Delta\right)$, it is straightforward to show that profits are lower than $R$. In order to get profits of $R$ (which are the maximum) the firm must tell the truth (to save on the reputation cost) and the customers must follow the firm's advice (to maximize their valuations). Clearly, this is impossible in these intervals.
} 
then when $\rho<p_{A}-p_{B}<(2 q-1) \Delta$ the equilibrium is non-revealing with both types saying $\hat{A}$.

Since prices can never be larger than $R$ without violating individual rationality, the maximum profits from setting prices in the intervals $p_{A}-p_{B}<-\Delta$ and $p_{A}-p_{B}>\Delta$ is $r$. Maximum profits from setting prices in the interval $\rho<p_{A}-p_{B}<(2 q-1) \Delta$ come from setting $p_{A}=R\left(\right.$ and $\left.p_{B} \geq R-(2 q-1) \Delta\right)$, which yields profits $R-(1-q) \rho$. In the interval $-\rho<p_{A}-p_{B}<\rho$ setting $p_{A}=p_{B}=R$ yields profits of $R$, which maximizes profits in the interval and overall.

\subsection{Proof of Proposition 3 (Full information)}

Whatever the price set by $A$, if $B$ undercuts it by setting $p_{B}<p_{A}-\Delta$, both type $A$ and type $B$ customers prefer to purchase product $B$, yielding profits $\pi_{A}=0$ and $\pi_{B}=p_{B}$ (and FI $B$ should set price $p_{B}=p_{A}-\Delta$ ). On the other hand, if $p_{A}-\Delta<p_{B}<\min \left(p_{A}+\Delta, R\right)$, type $A$ customers prefer product $A$ and type $B$ customers prefer product $B$, yielding profits $\pi_{A}=q p_{A}$ and $\pi_{B}=(1-q) p_{B}$ (and FI $A$ should set price $p_{B}=\min \left(p_{A}+\Delta, R\right)$ ). Finally, setting $p_{B}>p_{A}+\Delta$ would yield $\pi_{B}=0$, so FI $B$ will never price in this range.

FI $A$ 's strategy will be to set a price such that $B$ prefers not to undercut $A$. For this to occur, $B$ 's profits have to be at least as large by choosing a price in the $\left(p_{A}-\Delta, \min \left(p_{A}+\Delta, R\right)\right)$ range. That is,

$$
(1-q) \min \left(p_{A}+\Delta, R\right) \geq p_{A}-\Delta
$$

The optimal choice of $A$ happens to depend upon some conditions on the parameters:

- Case 1: $q R<2 \Delta$.

$A$ could choose to set a price $p_{A}<r$ or $p_{A}>r$.

- If FI $A$ chooses a price such that $p_{A} \leq r$, then $p_{A}+\Delta \leq R$. Since $q R<2 \Delta$ we have $q\left(p_{A}+\Delta\right)<2 \Delta$ and therefore, adding $p_{A}$ to both sides and rearranging, $p_{A}-\Delta \leq(1-q)\left(p_{A}+\Delta\right)$, so (7) is satisfied and $A$ gets profits $\pi_{A}=q p_{A}$. FI $A$ profits are locally maximized for $p_{A}=\min \left(r, \frac{2-q}{q} \Delta\right)$. Since $q R<2 \Delta$, dividing by $q$ and subtracting $\Delta$, yields that the minimum is reached for $p_{A}=r$. 
- If $p_{A}>r$, then $p_{A}+\Delta>R$ and $p_{B}=R$. FI $A$ will therefore choose the maximum price that satisfies (7), which is now $p_{A}=$ $\min [(1-q) R+\Delta, R]$.

If $\min [(1-q) R+\Delta, R]=R$, then FI $A$ profits are larger in the $p_{A}>r$ range as $R>r$.

If instead, $\min [(1-q) R+\Delta, R]=(1-q) R+\Delta$ this is also the case, since $q R<2 \Delta$ implies $(1-q) R+2 \Delta>R$ and therefore $(1-q) R+\Delta>r$.

- Case 2: $q R>2 \Delta$

Proceeding in the same way, consider the two strategies for FI $A$.

- $\quad$ - If FI $A$ chooses a price such that $p_{A} \leq r$, then $p_{A}+\Delta \leq R$, and condition $(7)$ becomes $(1-q)\left(p_{A}+\Delta\right) \geq p_{A}-\Delta$, which is equivalent to $p_{A} \leq \frac{2-q}{q} \Delta$. Since $q R>2 \Delta$ imply $r>\frac{2-q}{q} \Delta$, the best strategy for FI $A$ within $p_{A} \leq r$ range of prices is to set $p_{A}=\frac{2-q}{q} \Delta$.

- If $p_{A}>r$, then because $q R>2 \Delta$ implies $r>(1-q) R+\Delta$, we have $p_{A}-\Delta>(1-q) R$ and condition (7) is never satisfied, so it is never optimal for FI $A$ to choose a price $p_{A}>r$.

Consequently the best strategy in case 2 is to choose the best price for $p_{A} \leq r$, that is $p_{A}=\frac{2-q}{q} \Delta$, which proves proposition 3 .

\subsection{Proof of Lemma 4}

We will consider successively the different possible equilibria, which can be completely ordered by customer strategies $(a=1, b=1 ; a=0, b=1$; $a=1, b=0$; and $a=0, b=0)$ since assumption $\mathbf{A 2}$ allows us to disregard equilibria with interior values for $a$ or $b$.

- Case $1(a=1, b=0)$ Replacing these values in equations (2) and (3), we obtain $\Delta \pi_{A}(A)>0$ and $\Delta \pi_{A}(B)>0$ and there is full revelation with all customers buying $A$. The condition $\Delta U_{A}(\widehat{A})>0$ implies then $p_{A}<p_{B}+\Delta$, while $\Delta U_{A}(\widehat{B})<0$ implies the stronger condition $p_{A}<$ $p_{B}-\Delta$. As a consequence, the necessary and sufficient condition for this equilibrium to occur is $p_{A}<p_{B}-\Delta$, as stated in part 1 of the Lemma. 
- Case $2(a=1, b=1)$ Replacing these values in equations (2) and (3), we obtain $\Delta \pi_{A}(A)=p_{A}$ and $\Delta \pi_{A}(B)=-p_{A}+\rho$. As a consequence two cases are to be considered: $p_{A}<\rho$ and $p_{A}>\rho$ (equality is ruled out by assumption A2). In the first case, the equilibrium is fully revealing and the conditions for $a=1, b=1$ to be a solution is that $\Delta U_{A}(\widehat{A})>0$ and $\Delta U_{A}(\widehat{B})>0$ is fulfilled, so that $p_{B}-\Delta<p_{A}<p_{B}+\Delta$. Using $\Delta>\rho$ (from assumption A1) allows us to establish part 2 of the Lemma. On the other hand, if $p_{A}>\rho$ the sign of $\Delta \pi_{A}(B)$ is negative and there is no equilibrium revelation as every agent is given the message $\widehat{A}$. As a consequence, the conditional probability $p(A \mid \widehat{A})=q$, and, by ChoKreps $p(B \mid \widehat{B})=1$. Conditions $\Delta U_{A}(\widehat{A})>0$ and $\Delta U_{A}(\widehat{B})>0$ imply $\Delta U_{A}(\hat{A})=(2 q-1) \Delta-p_{A}+p_{B}>0$ and $\Delta U_{A}(\widehat{B})=\Delta-p_{B}+p_{A}>0$, proving part 3 of the lemma.

- Case $3(a=0, b=1$, Zero profits for FI $A)$

i) Replacing these values in equations (2) and (3), we obtain $\Delta \pi_{A}(A)=$ $\Delta \pi_{A}(B)=0$ : These conditions permit the FI to choose any strategy. To begin with, the FI may play a mixed strategy, with $\alpha, \beta \in(0,1)$. The inequalities $\Delta U_{A}(\hat{A})<0$ and $\Delta U_{A}(\widehat{B})>0$ hold for these values of $\alpha$ and $\beta$ if and only if $p_{A}>p_{B}+\max [(2 P(A \mid \hat{A})-1) \Delta,-(2 P(B \mid$ $\hat{B})-1) \Delta$. By definition, for $(\alpha, \beta) \neq(0,0)$ and $(\alpha, \beta) \neq(1,1), P(A \mid$ $\hat{A})=\frac{\alpha q}{\alpha q+\beta(1-q)}$ and $P(B \mid \hat{B})=\frac{(1-\beta)(1-q)}{(1-\alpha) q+(1-\beta)(1-q)}$. Define $\psi(\alpha, \beta)$ by $\psi(\alpha, \beta) \equiv \max \left[2 \frac{\alpha q}{\alpha q+\beta(1-q)}-1,1-2 \frac{(1-\beta)(1-q)}{(1-\alpha) q+(1-\beta)(1-q)}\right]$. It can be easily shown that for $\alpha>\beta, \psi(\alpha, \beta)=2 \frac{\alpha q}{\alpha q+\beta(1-q)}-1$. This expression is increasing in $\alpha$, implying that the minimum occurs when $\alpha=\beta$, when $\psi(\alpha, \alpha)=2 q-1$. Similarly if $\beta>\alpha, \psi(\alpha, \beta)=1-2 \frac{(1-\beta)(1-q)}{(1-\alpha) q+(1-\beta)(1-q)}$. This expression is increasing in $\beta$, and its minimum occurs when $\beta=\alpha$, for which $\psi(\beta, \beta)=2 q-1$. Finally, the maximum of $\psi(\alpha, \beta)$ is 1 . The necessary and sufficient condition for an equilibrium where FI $A$ uses a mixed strategy regarding revelation while customers buy $B$ is $p_{A}>p_{B}+\psi(\alpha, \beta)$. Using the minimum and maximum values for $\psi(\alpha, \beta)$ establishes part $4 \mathrm{a}$ of the Lemma and the range of values $(\alpha, \beta)$ for which the mixed strategy equilibrium holds.

ii) If, instead, the FI strategy is $(\alpha=1, \beta=1)$, announcing systematically $\widehat{A}, P(B \mid \widehat{B})$ is defined by out-of-equilibrium beliefs, and for each set of out-of-equilibrium beliefs we will obtain a different equilibria. 
Symmetrically, if $(\alpha=0, \beta=0)$, it is $P(A \mid \hat{A})$ that will be defined by out of equilibrium beliefs. Since on the equilibrium path the condition $p_{A}>p_{B}+(2 q-1) \Delta$ holds, we now have the second and third parts of part 4 of the Lemma.

iii) Combining the conclusions of i) and ii) we find that if the condition $p_{A}>p_{B}+\Delta$ holds, any FI strategy $(\alpha, \beta \in[0,1])$ will be an equilibrium where all customers purchase $B$. This is part 5 of the Lemma.

- Case $4(a=0, b=0)$ This is never an equilibrium. Indeed, it implies $\Delta U_{A}(\widehat{A})<0$ and $\Delta U_{A}(\widehat{B})<0$. Equations (2) and (3), become $\Delta \pi_{A}(A)=-p_{A}+\rho$ and $\Delta \pi_{A}(B)=p_{A}>0$. Two cases are therefore to be considered. If $\rho>p_{A}$, the equilibrium is fully revealing; if $\rho<p_{A}$, the FI only announces $\widehat{B}$ but the Cho-Kreps criterion allows us to infer that $P(A \mid \widehat{A})=1$.So, whatever the case, replacing $P(A \mid \widehat{A})=1$ in expressions (4) and (5) leads to $\Delta U_{A}(\widehat{A})+\Delta U_{A}(\widehat{B})=\Delta(2 P(B \mid \widehat{B})) \geq 0$, which is a contradiction.

\subsection{Proof of Proposition 5 (Competing Specialized Banks, FI $\mathrm{A}$ is the price leader)}

1) First assume that $p_{B}>\rho+\Delta$. Then the only region where FI $B$ makes positive profits is $p_{B}<p_{A}-(2 q-1) \Delta$. In this region FI $A$ makes zero profits, so FI $A$ must lower $p_{A}$ such that $p_{B}<\rho+\Delta$. It can do this by setting $p_{A}-(2 q-1) \Delta<\rho+\Delta$, or $p_{A}<\rho+2 q \Delta$.

For $\rho<p_{A}<\rho+2 q \Delta$, prices will be such that the equilibrium is nonrevealing and all customers purchase $A$, or partially revealing and all customers purchase $B$. FI $B$ will manipulate its price so that the second interval pertains if it can, which then implies FI $A$ should set its price such that $p_{A}<\rho$. However, if $\rho<(2 q-1) \Delta$ and FI $A$ sets its price equal to $(2 q-1) \Delta$, FI $B$ is unable to maneuver its price.

For $p_{A}<\rho$, the prices will determine whether $A$ fully reveals and everyone purchases at $A\left(p_{B}>p_{A}+\Delta\right)$ or whether $A$ fully reveals and everyone purchases at the bank which matches their type $\left(p_{B}<p_{A}+\Delta\right)$. Clearly the second has more interest for FI $B$, which then proves our conjecture.

2) First consider the situation where $p_{A}>\rho+\Delta$. Here FI $B$ will clearly not choose to be in the partially revealing interval where it gets zero profits 
$\left(p_{B}>p_{A}-(2 q-1) \Delta\right)$, but the other two regions involve FI $A$ getting zero profits, so it must be that $p_{A}<\rho+\Delta$.

Now consider $\rho+(2 q-1) \Delta<p_{A}<\rho+\Delta$. Unlike above, there is one region where both firms make positive profits: $p_{A}-\Delta<p_{B}<\rho$. Full information is revealed and customers follow the advice. The highest profits for FI $B$ come from setting its price at the maximum of the interval $(\rho)$ and earning $(1-q) \rho$. However, the region above is a non-revealing one, in which all customer purchase at FI $B$. Profits are maximized for $B$ by choosing the highest price in the interval, $p_{A}-(2 q-1) \Delta$, which yields expected profits $p_{A}-(2 q-1) \Delta-q \rho$. These profits are larger than $(1-q) \rho$ (taking into account that we are in the region $\left.\rho+(2 q-1) \Delta<p_{A}<\rho+\Delta\right)$, which means that $p_{A}$ should be set even lower.

Lastly, setting $p_{A}<\rho+(2 q-1) \Delta$ can produce two possible responses from FI $B$. If FI $B$ sets $p_{B}=p_{A}-\Delta$, FI $B$ fully reveals information and gets all of the customers. If FI $B$ sets $p_{B}=\rho$, it fully reveals and gets the customers who are the best match at this higher price. FI $A$ only makes positive profits in this second region, so the solution has FI $A$ setting its price so that FI $B$ prefers this choice.

3) The proof has the same flavor of the proof when only FI $B$ offers information, but we need to check at each point what information revelation regime FI $A$ is in, and whether customers might approach FI $A$ first instead.

Consider the situation where $p_{A}>\rho+\Delta$. FI $B$ will not choose to be in its partially revealing interval $\left(p_{B}>p_{A}-(2 q-1) \Delta\right)$ since it can be shown that customers will always go to FI $A$ and purchase there, leaving FI $B$ with zero profits. FI $B$ will choose to be in one of the other two regions, both of which involve FI $A$ getting zero profits, so it must be that $p_{A}<\rho+\Delta$.

Now consider $\rho+(2 q-1) \Delta<p_{A}<\rho+\Delta$. Unlike the previous interval, there is one region where FI $B$ fully reveals and customers follow its advice, i.e. both firms will make positive profits: $p_{A}-\Delta<p_{B}<\rho$ (in this region FI $A$ is in partial revelation regime $-p_{B}<\rho$ and $\rho+(2 q-1) \Delta<p_{A}$ imply $p_{B}+(2 q-1) \Delta<p_{A}$ - so all customers will visit FI $B$ first). The highest profits for FI $B$ come from setting its price at the maximum of the interval $(\rho)$ and earning $(1-q) \rho$. However, the region above is a non-revealing one, in which all customer approach FI $B$ first and purchase there. Profits are maximized for $B$ by choosing the highest price in the interval, $p_{A}-(2 q-1) \Delta$, which yields expected profits $p_{A}-(2 q-1) \Delta-q \rho$. These profits are larger than $(1-q) \rho$ (taking into account that we are in the region $\rho+(2 q-1) \Delta<p_{A}<\rho+\Delta$ ), 
which means that $p_{A}$ should be set even lower.

Lastly, we look at $p_{A}<\rho+(2 q-1) \Delta$. As before, if FI $B$ sets $p_{B}<p_{A}-\Delta$, FI $B$ fully reveals information and gets all of the customers. For the region $p_{A}-\Delta<p_{B}<\rho$, FI $B$ is in a fully revealing regime where customers follow its advice. Note that for this given range of $p_{B}$ it is weakly dominant for customers to approach FI $B$ first (in fact the only time there is indifference is if FI $A$ is in a fully revealing regime as well). Therefore both FI $A$ and FI $B$ make positive profits in this region. FI $A$ consequently would like to insure that FI $B$ prefers this region. It is possible hat FI $B$ may want to set its price even higher than $\rho$ here. If it does so, it will be in a partial revelation regime. Since it will make zero profits if customers approach it first, FI $B$ needs FI $A$ to be in a full revelation following regime to make profits. For FI $A$ to be in a full revelation regime there are two possibilities.

The first possibility occurs when $\rho-(2 q-1) \Delta<p_{B}<\rho+\Delta$ and $p_{B}-\Delta<p_{A}<\rho$. Here it is clear that FI $A$ prefers to set $p_{A}$ as high as possible $(\rho)$ and FI $B$ can then follow by setting $p_{B}$ as high as possible $(\rho+\Delta)$. Notice here that FI $B$ is free riding off of the information of FI $A$ in order to set a higher price. However, profits for FI $A$ would be less than it would get by pricing higher and forcing FI $B$ to be the information provider $(q \rho<q \min [(1-q) \rho+\Delta, \rho+(2 q-1) \Delta])$.

The second possibility occurs when $p_{B}<\rho-(2 q-1) \Delta$ and $p_{B}-\Delta<$ $p_{A}<p_{B}+(2 q-1) \Delta$. The maximum return for FI $B$ would be setting $p_{B}=\rho-(2 q-1) \Delta$, in which case $p_{A}=\rho$, however this is also dominated by the above equilibrium.

\subsection{Proof of the payoffs in Figure 4 (Competing Spe- cialized Banks, $\mathrm{B}$ is the price leader)}

1) Only FI B invests in information: As long as $p_{B}>\rho$, FI $A$ has an incentive to set its price just below $p_{B}+(2 q-1) \Delta$, which leads to zero profits for FI $B$. If $p_{B}<\rho$, FI must price below $p_{B}+\Delta$ in order to make positive profits. Therefore the equilibrium is $p_{B}=\rho, p_{A}=\rho+\Delta$.

2) Only FI A invests in information: When $p_{B}>\rho-(2 q-1) \Delta$, the best response for FI $A$ is always to price slightly under $p_{B}+(2 q-1) \Delta$ and not reveal any information (always say $\hat{A}$ ). Since all customers then purchase $A$, this yields profits of zero for FI $B$. If $\rho<(2 q-1) \Delta$, this is what occurs and the price of FI $B$ is undetermined, as any price yields zero profits. If 
$\rho>(2 q-1) \Delta$, then FI $B$ will set its price below $\rho-(2 q-1) \Delta$. FI $A$ has two options, setting a price of $p_{B}-\Delta$, fully revealing, and getting all of the customers, or setting a price of $\rho$, fully revealing but sharing the customers. FI $B$ clearly prefers the second option and must set $p_{B}$ such that $p_{B}-\Delta<q \rho$ (FI $A$ prefers the second option). Since $\rho-(2 q-1) \Delta<q \rho+\Delta$, FI $B$ sets its price at $\rho-(2 q-1) \Delta$.

3) Both FIs invest in information: When $p_{B}>\rho+\Delta$, any price that FI $A$ charges which gives it positive profits gives FI $B$ zero profits.

When $\rho-(2 q-1) \Delta<p_{B}<\rho+\Delta$, we must look carefully at the possible best response of FI $A$ :

- If $p_{B}-\Delta<p_{A}<\rho$, FI $A$ will fully reveal with customers taking its advice. Indeed, FI $B$ will do the same (since $\left.p_{A}-(2 q-1) \Delta<\rho\right)$, so it does not matter where customers go first and the solution (restricting FI $A$ to this interval $)$ is $p_{B}=\rho+\Delta$ with profits $(1-q)(\rho+\Delta)$ and $p_{A}=\rho$ with profits $q \rho$.

- If $\rho<p_{A}<p_{B}+(2 q-1) \Delta$, FI $A$ reveals nothing and the only possible chance for both to make positive profits is for FI $B$ to be in a fully revealing regime. Since the interval for $p_{A}$ implies that $p_{B}>p_{A}-(2 q-$ $1) \Delta$, to get a fully revealing regime we must have $p_{A}-(2 q-1) \Delta<\rho$. Hence a candidate solution here is $p_{B}=\rho$ with profits $(1-q) \rho$ and $p_{A}=\rho+(2 q-1) \Delta$ with profits $q(\rho+(2 q-1) \Delta)$.

- If $p_{A}>p_{B}+(2 q-1) \Delta$, FI $A$ is partially revealing. Hence it will only choose this interval if FI $B$ is fully revealing. The maximum price for FI $B$ to fully reveal is $\rho$ which limits FI $A$ to a price of $\rho+\Delta$ (the profits are $(1-q) \rho$ and $q(\rho+\Delta)$ for FI $B$ and FI $A$ respectively).

- Lastly, if $p_{A}<p_{B}-\Delta$, FI $A$ fully reveals and gets all of the customers. Hence its profits are $p_{B}-\Delta$.

The profits of $p_{B}-\Delta$ for FI $A$ proves that there is a profitable deviation from the $p_{B}=\rho+\Delta$ candidate solution. Since FI $A$ prefers to set $p_{A}=\rho+\Delta$ (rather than $\rho+(2 q-1) \Delta$ ) and a deviation downward as before (to $\rho-\Delta$ ) is impossible, the solution for this interval of $p_{B}$ is $p_{B}=\rho$ and $p_{A}=\rho+\Delta$.

Finally, any profits gained from FI $B$ setting $p_{B}<\rho-(2 q-1) \Delta$ will be lower than those when $p_{B}=\rho$ because of the lower price and the fact that FI $A$ will only either share or take all of the customers. 


\subsection{Robustness of the model to more general reputa- tion costs}

In our model, a FI bears a reputation cost if i) it lies to a customer and ii) it profits from its lie because this lie leads the customer to purchase from him. Since other definitions of reputation costs are possible, in this subsection we check whether the model is robust to a more general specification of reputation costs. In order to do this we focus on the case where FI A is the price leader and FI B is the firm which has invested in information provision. This is the main case in our model as we have stated in Proposition 6. Previously, we saw that the ex-ante disadvantage of FI B forced it into information revelation, which forms the basis of our main results.

We allow for two reputation costs. One reputation cost, $\gamma$, is incurred when the FI lies and misleads the customer into purchasing the wrong product. This occurs when FI B tells a B-customer that he is type A and the customer purchases A (a case that entails no reputation cost in our model) and when it tells an A-customer that she is type B and the customer purchases B (a case that we cover in our model). The other reputation cost, $\eta$, is incurred when the FI lies but doesn't mislead the customer. This occurs when FI B tells a B-customer that he is type A and the customer purchases $\mathrm{B}$ and when it tells an A-customer that she is type $\mathrm{B}$ and the customer purchases A. We assume $\gamma>\eta$. This is represented in Figure 3 .

For this subsection, we abandon assumption A2. As we will see, there is a non-trivial partially revealing equilibria which would be eliminated with assumption A2 (and leave no equilibria for a range of possible prices).

1. We begin by analyzing the signaling game for FI B. For brevity, when customers use pure strategies we only describe the equilibrium, as its derivation is quite similar to our previous analyses.

- Hence, for $p_{B} \leq p_{A}-\Delta$, FI B fully reveals and all customers purchase $B$.

- When $p_{B} \geq p_{A}+\Delta$, FI B fully reveals and all customers purchase A.

- When $p_{A}-\Delta \leq p_{B} \leq p_{A}+\Delta$ and $p_{B} \leq \gamma$, FI B fully reveals and customers follow the advice.

- When $p_{A}-\Delta \leq p_{B} \leq p_{A}-(2 q-1) \Delta$ and $p_{B} \geq \gamma$, FI B always says $\hat{B}$, and customers purchase $B$. 


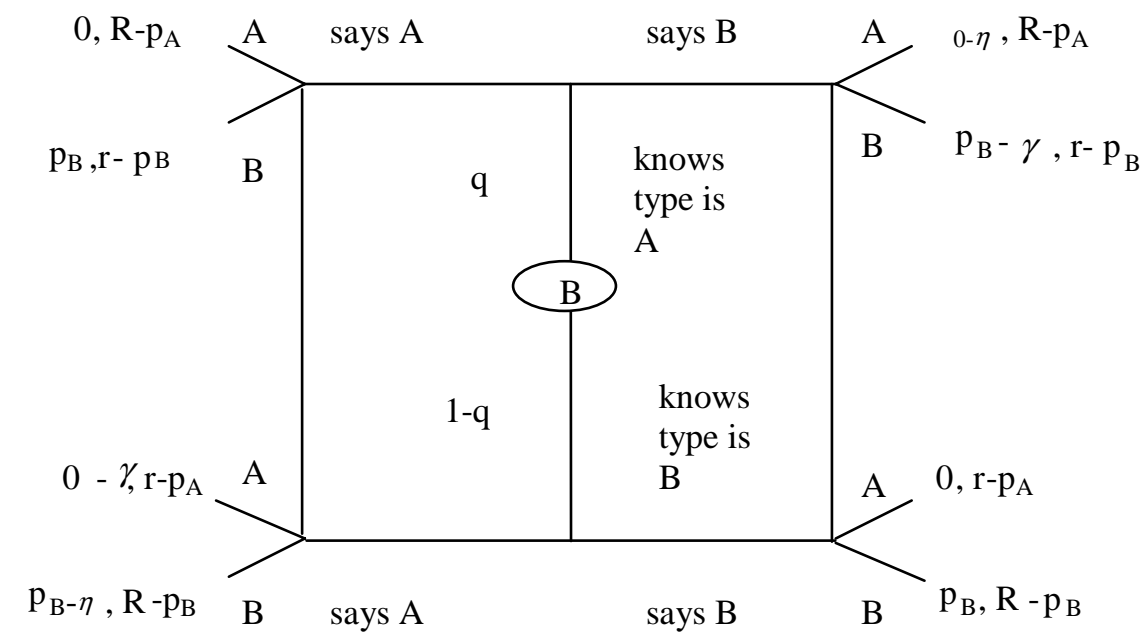

Figure 3: The signaling game with general reputation costs

- When $p_{A}-(2 q-1) \Delta \leq p_{B} \leq p_{A}-\Delta$ and $p_{B} \geq \gamma$ there is one partially revealing equilibrium, where FI B is indifferent between saying $\hat{A}$ and $\hat{B}$ to an A customer, but always says $\hat{B}$ to a $\mathrm{B}$ customer. Customer's who hear $\hat{B}$ then are indifferent between purchasing $A$ or $B$. Let $y$ equal the probability with which FI B says $\hat{B}$ to an A customer. The customer who hears $\hat{B}$ updates her probability of being type $\mathrm{B}$ to equal $\frac{1-q}{1-q+y q}$. She is then indifferent when $p_{B}=p_{A}+\left(2\left(\frac{1-q}{1-q+y q}\right)-1\right) \Delta$ (since $y \in[0,1], p_{B} \in\left[p_{A}-\right.$ $\left.\left.(2 q-1) \Delta, p_{A}+\Delta\right]\right)$. Customer's who hear $\hat{A}$ know they are type $A$, and since $p_{B} \geq p_{A}-\Delta$, they purchase $A$. In order to make FI $\mathrm{B}$ indifferent, the customer at $\hat{B}$ then chooses $B$ with probability $\frac{\eta}{\eta+p_{B}-\gamma}$ (which also implies that a necessary condition is that $p_{B} \geq$ $\gamma)$. Profits from partially revealing are $(1-q)\left(\frac{\eta}{\eta+p_{B}-\gamma}\right) p_{B}$. Profits are decreasing in $p_{B}$ (using the assumption $\gamma>\eta$ ), meaning that FI $B$ has the incentive to set its price at the bottom of the interval.

2. Competition between FI A and FI B can also be analyzed in a similar way as before. 
- First, we show that $p_{A}$ is below $\gamma+\Delta$. If it were above, there would be four possible information regimes: fully revealing where all customers purchase $\mathrm{B}\left(p_{B} \leq p_{A}-\Delta\right)$, non-revealing in $\hat{B}$ where all purchase $\mathrm{B}\left(p_{A}-\Delta \leq p_{B} \leq p_{A}-(2 q-1) \Delta\right)$, partially revealing $\left(p_{A}-(2 q-1) \Delta \leq p_{B} \leq p_{A}+\Delta\right)$, and fully revealing where all buy $\mathrm{A}\left(p_{B} \geq p_{A}+\Delta\right)$. FI $\mathrm{B}$ will never set the price so high that everyone purchases $A$, so we can focus on the first three intervals. The only interval where FI A makes positive profits is the partially revealing one - hence we will show that FI B can make larger profits by not pricing in that interval. We will show this in a proof by contradiction.

Suppose the profits from the partially revealing interval are larger than those of the non-revealing interval. If FI B sets its price in the non-revealing interval, it will choose the highest element, $p_{A}-(2 q-1) \Delta$. Likewise, in the partially revealing interval, the price that maximizes profits is $p_{A}-(2 q-1) \Delta$. The hypothesis to be contradicted is then:

$\pi_{\text {non-revealing }}<\pi_{\text {partially-revealing }}$ or $p_{B}-q \gamma<(1-q)\left(\frac{\eta}{\eta+p_{B}-\gamma}\right) p_{B}$

where $p_{B}=p_{A}-(2 q-1) \Delta$.

Since $p_{B}>\gamma$, substituting $\gamma$ for $p_{B}$ on the left hand side gives us

$$
(1-q) \gamma<(1-q)\left(\frac{\eta}{\eta+p_{B}-\gamma}\right) p_{B}
$$

Re-arranging this expression yields $p_{B}<\gamma$, which is a contradiction and proves our result.

- Next, we show that $p_{A}$ won't be in the interval $(\gamma-(2 q-1) \Delta, \gamma+\Delta]$. The information revelation regimes for this interval are the same as above with the exception that the interval $p_{A}-\Delta \leq p_{B} \leq p_{A}-(2 q-1) \Delta$ is broken into two parts now: there is full revelation with customers following advice when $p_{A}-\Delta \leq p_{B} \leq \gamma$, and the same non-revealing regime as above when $\gamma \leq p_{B} \leq p_{A}-(2 q-1) \Delta$. Once again, FI B won't set its price so high that everyone purchases $A$, nor will it set its price in the partially revealing region since the above proof holds here as well. Lastly, it is easy to see that the non-revealing region 
yields higher profits for B than the region where FI B fully reveals and customers follow advice (since $p_{B}-q \gamma>(1-q) \gamma$ ), meaning that FI A would get zero profits.

- Finally we look for the equilibrium such that $p_{A} \leq \gamma-(2 q-1) \Delta$. Now there are four information revelation regimes: fully revealing where all customers purchase $\mathrm{B}\left(p_{B} \leq p_{A}-\Delta\right)$, fully revealing where customers follow advice $\left(p_{A}-\Delta \leq p_{B} \leq \gamma\right)$, partially revealing $\left(\gamma \leq p_{B} \leq p_{A}+\Delta\right)$, and fully revealing where all buy $\mathrm{A}\left(p_{B} \geq p_{A}+\Delta\right)$. The maximum profits of FI B for both the fully revealing regime where customers follow advice and for the partially revealing regime comes when $p_{B}=\gamma$ and is equal to $(1-q) \gamma$ (for both). The maximum profits of FI B in the fully revealing all-purchase-B regime is $p_{A}-\Delta$. Therefore the optimal price for FI A is

$p_{A}=\min [\gamma-(2 q-1) \Delta,(1-q) \gamma+\Delta]$, where the second element prevents FI B from pricing low and giving FI A zero profits.

The profits take the same form as our model with more restrictive reputation costs, namely $\pi_{A}=q p_{A}$ and $\pi_{B}=(1-q) \gamma-f$. There are however, multiple equilibria which give us this same result - one fully revealing and many partially revealing. The many partially revealing come from the corner solution that customers who hear $\hat{B}$ always choose B. Since FI B gets zero when the customer is type A, FI B is indifferent about what it says to type A, meaning that any probability $y$ of saying $\hat{B}$ must only make the customer strictly prefer product B. Using weak dominance (as we did in the text, see footnote 6 ) gets rid of all partially revealing equilibria (FI B weakly prefers saying $\hat{A}$ to type A when $p_{B}=\gamma$ ), leaving us with essentially the same equilibrium as in our less general reputation cost model. 